\title{
Fracture Mechanics Models for Brittle Failure of Bottom Rails due to Uplift in Timber Frame Shear Walls
}

\author{
Joergen L. Jensen, Giuseppe Caprolu, and Ulf Arne Girhammar \\ Division of Wood Science and Engineering, Luleå University of Technology, 93187 Skellefteå, Sweden \\ Correspondence should be addressed to Ulf Arne Girhammar; ulf.arne.girhammar@ltu.se
}

Received 21 May 2016; Accepted 17 July 2016

Academic Editor: John Mander

Copyright (C) 2016 Joergen L. Jensen et al. This is an open access article distributed under the Creative Commons Attribution License, which permits unrestricted use, distribution, and reproduction in any medium, provided the original work is properly cited.

\begin{abstract}
In partially anchored timber frame shear walls, hold-down devices are not provided; hence the uplift forces are transferred by the fasteners of the sheathing-to-framing joints into the bottom rail and via anchor bolts from the bottom rail into the foundation. Since the force in the anchor bolts and the sheathing-to-framing joints do not act in the same vertical plane, the bottom rail is subjected to tensile stresses perpendicular to the grain and splitting of the bottom rail may occur. This paper presents simple analytical models based on fracture mechanics for the analysis of such bottom rails. An existing model is reviewed and several alternative models are derived and compared qualitatively and with experimental data. It is concluded that several of the fracture mechanics models lead to failure load predictions which seem in sufficiently good agreement with the experimental results to justify their application in practical design.
\end{abstract}

\section{Introduction}

A plastic analysis and design method for light-frame timber shear walls have been presented; see, for example, Källsner and Girhammar [1]. In partially anchored shear walls, the leading stud is not fully anchored against uplift and the corresponding tying down forces will develop instead in the sheathing-to-framing joints along the bottom rail. These tying down forces in the joints will, among other things, introduce crosswise bending of the bottom rail with possible splitting failure along the bottom of the rail. Also, splitting of the bottom rail along the row of the sheathing-to-framing joints can occur.

In the European timber code, Eurocode 5 [2], no design recommendations are given regarding these kinds of splitting failure of the bottom rail, although the European Standard EN 594 [3] addresses the problem of cupping of the bottom rail due to uplift of the loaded end.

Experimental works devoted to the specific question of anchoring the bottom rail with respect to both shear and tensile forces are very scarce. Prion and Lam [4] pointed out the fact that when designing shear walls, it is important to understand the differences between hold-downs at the leading stud and anchor bolts of the bottom rail. In case of no hold-downs and in order to prevent these brittle failure modes, they discussed the need to use large washers to transfer the eccentric loads from the sheathing through the nails into the bottom rail and to the anchor bolts and foundation. $\mathrm{Ni}$ and Karacabeyli [5] presented two methods, one empirical and one mechanics-based, to account for the partial uplift when no hold-down connections are used. Most studies have so far been devoted to the lateral (shear) resistance of anchorbolt joints between bottom rails and foundations; see, for example, Hirai et al. [6-8] and Namura et al. [9]. Leitch et al. [10], Leitch [11], and Menendez et al. [12] noted the importance of a robust bottom rail connection and its ability to offer secure anchorage, with respect to both lateral (shear) and overturning forces. Duchateau [13] studied the uplift resistance of bottom rails in wood shear walls without holddowns in order to maintain bottom rail structural integrity. Yeh and Williamson [14] presented an experimental study on the combined shear and uplift resistance of wood structural panel shear walls. In the NAHB report [15], an experimental study is presented, where four types of partially anchored shear walls with varying nail size and spacing and with small round or big square washers were tested. Splitting both along 
TABLE 1: Specification of specimen tested in study A and study B. Notation: SS = single-sided specimens, DS $=$ double-sided specimens, $b=$ width of rail, and $s=$ distance from washer edge to loaded edge of the bottom rail (cf. Figure 1).

\begin{tabular}{|c|c|c|c|c|c|c|c|c|}
\hline \multirow{3}{*}{ Series } & \multirow{3}{*}{ Set } & \multicolumn{2}{|c|}{ Study A } & \multicolumn{2}{|c|}{ Study B } & \multirow{3}{*}{$\begin{array}{c}\text { Anchor bolt position } \\
{[\mathrm{mm}]}\end{array}$} & \multirow{3}{*}{$\begin{array}{l}\text { Size of washer } \\
{[\mathrm{mm}]}\end{array}$} & \multirow{3}{*}{$\begin{array}{c}\text { Distance } s \\
{[\mathrm{~mm}]}\end{array}$} \\
\hline & & \multicolumn{2}{|c|}{ Number of tests } & \multicolumn{2}{|c|}{ Number of tests } & & & \\
\hline & & SS & DS & SS & DS & & & \\
\hline \multirow{5}{*}{1} & $1-B C(A)^{a}$ & - & - & - & 16 & \multirow{5}{*}{$\begin{array}{c}b / 2 \\
60 \mathrm{~mm} \text { from sheathing }\end{array}$} & $40 \times 40 \times 15$ & 40 \\
\hline & 1 & 10 & 10 & 16 & 16 & & $40 \times 40 \times 15$ & 40 \\
\hline & 2 & 10 & 10 & 16 & 16 & & $60 \times 60 \times 15$ & 30 \\
\hline & 3 & 10 & 10 & 16 & 16 & & $80 \times 70 \times 15$ & 20 \\
\hline & 4 & 10 & 10 & 16 & 16 & & $100 \times 70 \times 15$ & 10 \\
\hline \multirow{3}{*}{2} & 1 & 10 & \multirow{3}{*}{ - } & 14 & & \multirow{3}{*}{$\begin{array}{c}3 b / 8 \\
45 \mathrm{~mm} \text { from sheathing }\end{array}$} & $40 \times 40 \times 15$ & 25 \\
\hline & 2 & 10 & & 16 & - & & $60 \times 60 \times 15$ & 15 \\
\hline & 3 & 10 & & 16 & & & $80 \times 70 \times 15$ & 5 \\
\hline \multirow{2}{*}{3} & 1 & 10 & \multirow{2}{*}{-} & 16 & - & \multirow{2}{*}{$\begin{array}{c}b / 4 \\
30 \mathrm{~mm} \text { from sheathing }\end{array}$} & $40 \times 40 \times 15$ & 10 \\
\hline & 2 & 9 & & 16 & & & $60 \times 60 \times 15$ & 0 \\
\hline
\end{tabular}

${ }^{\mathrm{a}}$ Set with boundary conditions as study A.

the bottom side and along the edge side of the bottom rail occurred.

The problem of splitting of the bottom rail in partially anchored shear walls due to uplift has, with respect to the focus of this paper, previously been studied by Girhammar and Källsner [16], with an empirical approach, and by Serrano et al. [17] and Caprolu et al. [18], with an analytical treatment. In Serrano et al. [19] and Serrano et al. [17], a comparison between a finite element analysis and analytical solutions was made. In Caprolu et al. [18], a comparison was made between the analytical models and experimental results. In the present paper, the models presented in these papers are reviewed and alternative models are derived. Model predictions are compared with experimental data previously presented in Caprolu et al. [20, 21]. For further work, see also Caprolu et al. [22] discussed in Section 4 as the last paragraph.

\section{Experimental Background}

An experimental background based on Caprolu et al. [20, $21]$ is reviewed here. The aim of this section is to give the essential information needed to understand and evaluate the capabilities of the fracture mechanics models presented.

2.1. Test Specimen and Material Properties. The specimen was made up of a bottom rail joined to sheathing by nails. The material properties were as follows:

(i) Bottom rail: spruce (PiceaAbies), C24 according to EN 338 [23].

(ii) Sheathing: hardboard, $8 \mathrm{~mm}$ (wet process fibre board, HB.HLA2, EN 622-2 [24], Masonite AB).

(iii) Sheathing-to-timber joints: annular ringed shank nails, $50 \times 2.1 \mathrm{~mm}$ (Duofast, Nordisk Kartro AB). The holes in the sheathing were predrilled, $1.7 \mathrm{~mm}$.

(iv) Anchor bolt: $\phi 12$ (M12). The holes in the bottom rail were predrilled $13 \mathrm{~mm}$.
2.2. Test Programme and Setup. Two studies on the splitting failure capacity of bottom rail were carried out, here called study A and study B. Both of them studied bottom rails with single- and double-sided sheathing. The differences between the two studies were for single-sided sheathing. (1) The boundary conditions: details can be found in Caprolu et al. $[20,21]$. In study $A$, the load was applied in a distributed way while in study B a hinge was created allowing the specimen to rotate. (2) The nail spacing in the sheathing-to-framing joints: in study A, the nail spacing was $50 \mathrm{~mm}$ for series 1 and $25 \mathrm{~mm}$ for series 2 and 3, while in study B it was $50 \mathrm{~mm}$ for all specimens. (3) The torque used to tighten the bolts: $40 \mathrm{Nm}$ was applied in study $\mathrm{A}$ and $50 \mathrm{Nm}$ in study B. (4) The displacement rate: $2 \mathrm{~mm} / \mathrm{min}$ was used in study A and, by mistake, $10 \mathrm{~mm} / \mathrm{min}$ was used in study B. For double-sided sheathing, the only difference between the two studies was the boundary conditions. The main aim of the experimental programme was to study the influence of the distance between the edge of the washer and the loaded edge of the bottom rail, here denoted as $s$, on the failure load and mode of the bottom rail. The distance was varied changing the washer size and the anchor-bolt position according to Table 1 for specimens with single-sided sheathing, and only the washer size for specimens with double-sided sheathing, where the anchor bolt was kept at the centre of the bottom rail for all tests. The specimens were fixed to a supporting structure and loaded with an uplifting load. Figures 1(a) and 1(b) show the test setup of the experiments for single- and double-sided sheathing, respectively.

In Table 1, the test program of studies A and B is specified.

\subsection{Test Programme and Setup}

2.3.1. Failure Modes. Three primary failure modes as shown in Figure 2 were found during the experimental programmes:

(i) Mode 1: splitting along the bottom side of the rail according to Figure 2(a). 


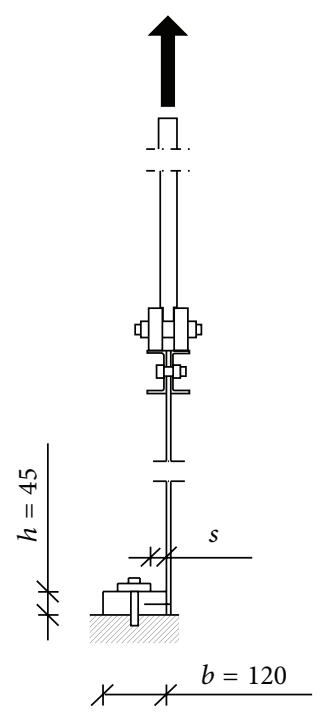

(a)

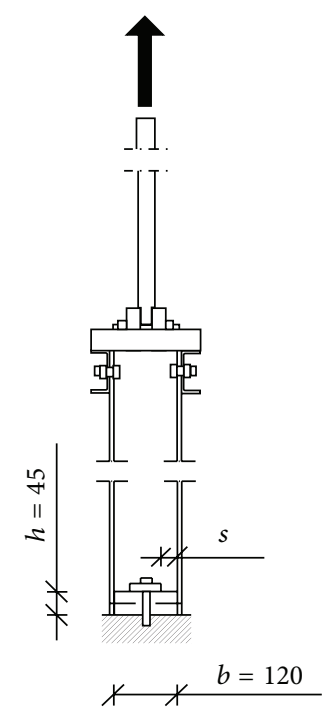

(b)
FIGURE 1: Cross section view of the specimen tested: (a) single-sided sheathing and (b) double-sided sheathing.

(ii) Mode 2: splitting along the edge side of the rail according to Figure 2(b).

(iii) Mode 3: yielding and withdrawal of the nails in the sheathing-to-framing joints according to Figure 2(c).

The failure mode was found to be mainly dependent on the distance $s$ in both studies. For distance $s \geq 20 \mathrm{~mm}$, failure mode 1 was the only failure mode, while for distance $s \leq$ $20 \mathrm{~mm}$, failure modes 2 and 3 also appeared (for specimens with pith upwards and single-sided sheathing, the limit for exclusion of failure modes 2 and 3 was $s \geq 25 \mathrm{~mm}$ ).

2.3.2. Failure Loads and Crack Development. In Tables 2 and 3 , the failure load recorded during the experimental studies is listed. Table 2 refers to specimens with pith oriented upwards and Table 3 to specimens with pith oriented downwards. The mean failure load for each set is shown. Further, the mean failure load for each failure mode, according to Figure 2, is listed. In each table, specimens with both single- and doublesided sheathing are included.

Since the tests were a collection of data for a future fracture mechanics approach, the crack characteristics, that is, path and length, were studied. It was found that the crack formation depends on the bolt position, the pith orientation, and the annual ring pattern.

For specimens with single-sided sheathing and pith upwards (PU), three types of cracks were found for mode 1 and one for failure mode 2, as shown in Figure 3. In the same figure, the cracks for double-sided sheathing are also shown, for which two additional types of cracks for failure mode 1 and one additional type for failure mode 2 have been found, with respect to specimens with single-sided sheathing. For failure mode 1 , the crack always initiates at the bottom side of the bottom rail, usually in line with the bolt position along the width of the bottom rail, and then it develops in most specimens vertically in a straight line across the annual rings towards the pith (Figure 3(a)) or the crack initiates off the centre and propagates in a straight line towards the pith (Figure 3(b)). In some cases, the crack develops vertically for a certain length and then changes direction following the annual rings (Figure 3(c)). For specimens with double-sided sheathing in Figures 3(d) and 3(e), two additional crack paths are shown: the one in Figure 3(d) occurred only twice and the crack probably propagates in this way because it finds a weaker crack plane, while the crack shape in Figure 3(e) is affected by the pith position. In all other specimens, the pith was on the border of the rail and more or less at the middle of the cross section width. Usually the crack propagates towards the pith.

The crack for failure mode 2 is always initiated at the nails in the sheathing-to-framing joint and it propagates horizontally for a certain length and then deviates in a more vertical direction across the annual ring (Figure 3(f)) or, for doublesided sheathing, following the annual rings (Figure 3(g)).

In Figure 4, examples of cracks for specimens with pith downwards are shown for specimens with both single and double-sided sheathing. The crack characteristics are similar to those of specimens with pith upwards. The crack starts at the bottom side of the rail and develops vertically in a straight line (Figure $4(\mathrm{a})$ ) or in an oblique line towards the loaded edge of the bottom rail (Figure 4(b)), the latter only for singlesided specimens. In some cases, the crack starts along the annual rings and then it changes in vertical direction across the annual rings (Figure 4(c)) or "jumps" to another annual ring and then follows again its orientation (Figure 4(d)), the latter only in double-sided specimens. In Figure 4(e) an unusual "zig-zag" crack path is shown for a double-sided specimen. For failure mode 2 , the crack appears at the line of the nails and propagates horizontally a certain length before it follows the annual rings (Figure 4(f)).

For most of the specimens, the distance between the position of crack initiation and the edge of the bottom rail, denoted as $b_{\text {crack1 } 1}$ in Figures 3 and 4 , was measured on the end of the bottom rail for failure mode 1 . For failure mode 2 , the length of the horizontal part of the crack before it changes direction, denoted as $b_{\text {crack } 2}$ in Figures 3 and 4 , was measured. In Caprolu et al. [20, 21], the measured $b_{\text {crack } 1}$ and $b_{\text {crack2 }}$ values are listed. In Tables 4 and 5 the measured values for $b_{\text {crack2 }}$ are presented for specimens with pith upwards and downwards, respectively.

\section{Theory}

A linear elastic body with a preexisting crack with area $A$ is considered. The body is subjected to a single-force, $P$, and the value $P_{u}$, which causes the preexisting crack to propagate, is sought. The so-called compliance method of fracture mechanics, which follows from simple energy considerations, leads to [25-30]

$$
P_{u}=\sqrt{\frac{2 \mathscr{G}_{f}}{d C(A) / d A}},
$$



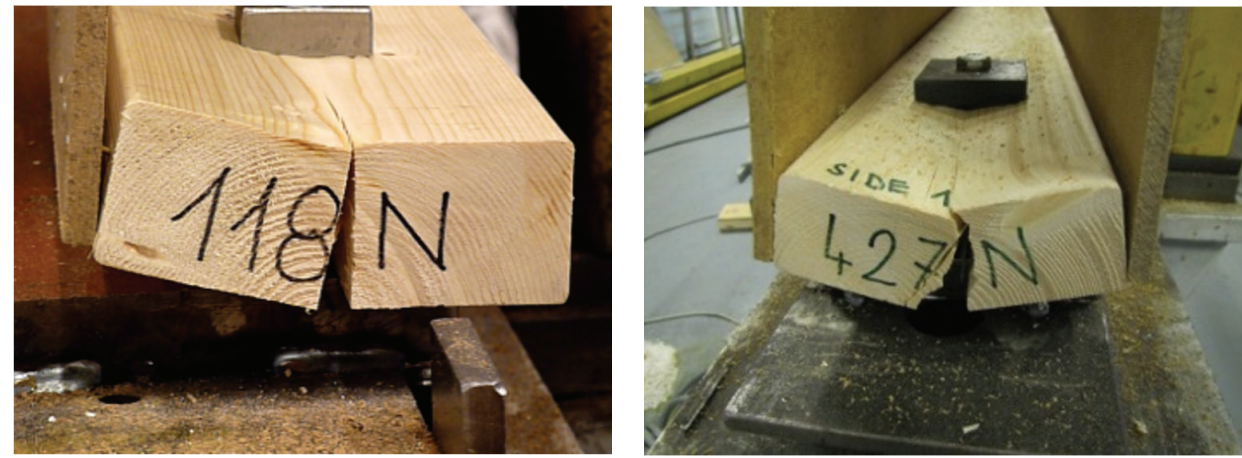

(a) Mode 1
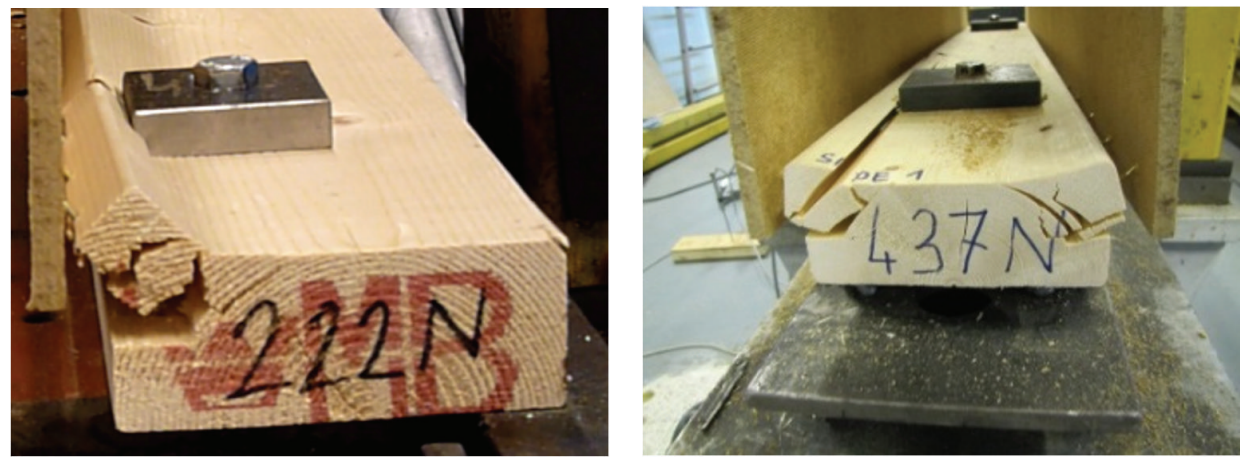

(b) Mode 2
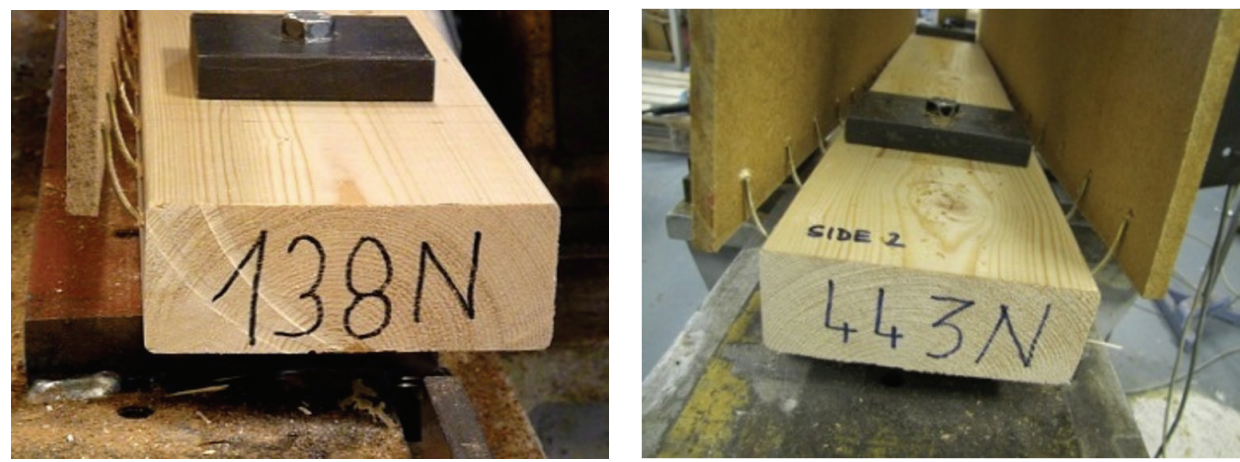

(c) Mode 3

Figure 2: (a) Splitting failure along the bottom side of the rail; (b) splitting failure along the edge side of the rail; and (c) yielding and withdrawal of the nails in the sheathing-to-framing joints.

where $P_{u}$ is the failure load, $\mathscr{G}_{f}$ is the fracture energy, $A$ is the crack area, and $C$ is the compliance, that is, the deflection at the loading point for a unit force.

Bottom rails in partially anchored shears wall are subjected to uplift forces from the sheathing (see, e.g., Ni and Karacabeyli [5, 31], Girhammar and Källsner [16], and Caprolu et al. [18]) which may result in splitting of the bottom rail. Experiments show (Figure 2) that cracks may form either at the bottom side of the rail and propagate vertically (mode 1 ) or at the side of the rail and propagate horizontally (mode 2). The first type is presented in Serrano et al. [17] and both types of cracks are treated in Serrano et al. [19] and Caprolu et al. [18], and a fracture mechanics solution based on (1) is derived.
In the present paper, the existing fracture mechanics model is reviewed and alternative models also based on (1) are derived and compared with each other and with the experimental data presented in Section 2.

\subsection{Horizontal Cracking (Mode 2)}

3.1.1. Model 1. Figure 5 shows the geometry, boundary conditions, and loading conditions assumed in Serrano et al. [19] and Caprolu et al. [18] for a crack propagating horizontally in a bottom rail.

The out-of-plane width of the bottom rail is denoted as $b$, and the crack is assumed to propagate simultaneously over 
TABLE 2: Results from testing of specimens with the pith oriented upwards (PU). Failure modes are defined in Figure 2.

(a) Study A

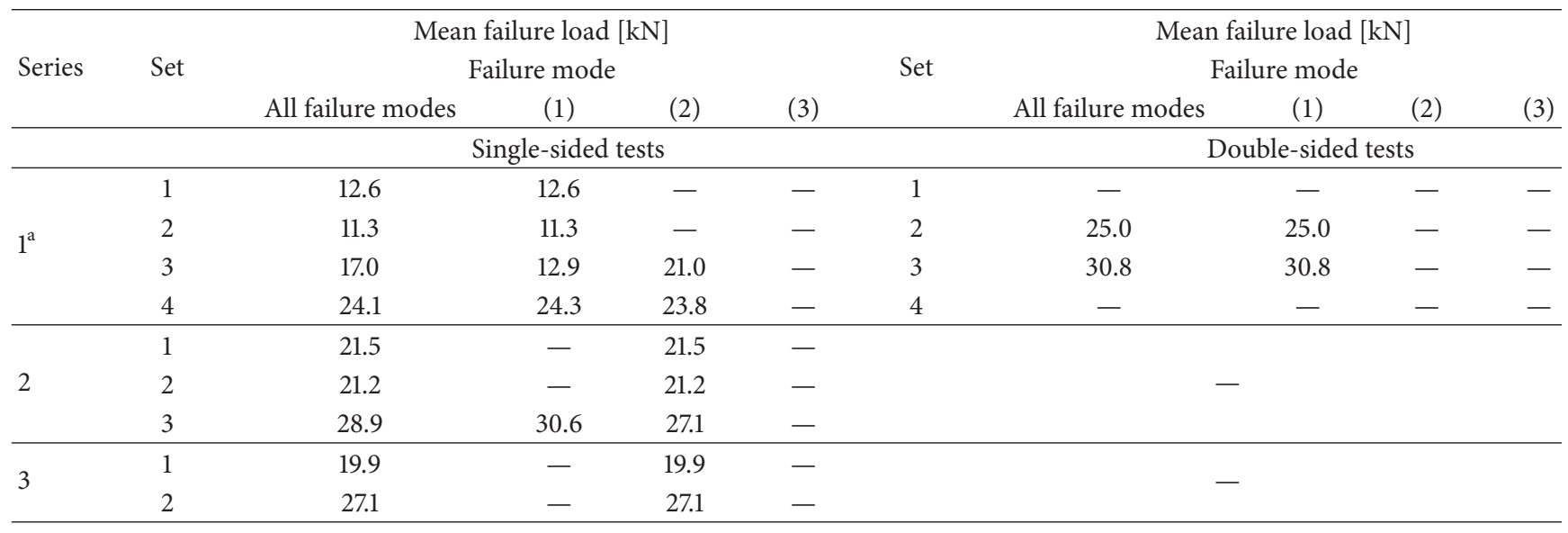

(b) Study B

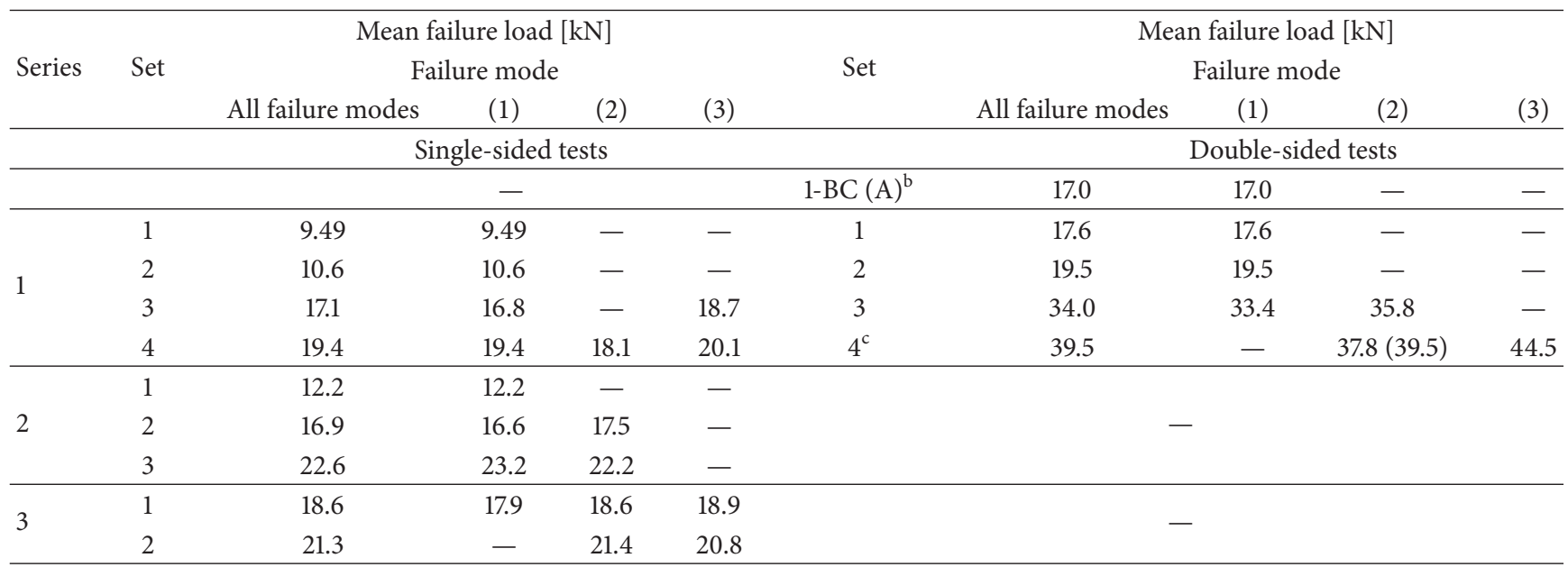

${ }^{\mathrm{a}}$ Series 1 of study A had a nail distance of $50 \mathrm{~mm}$ instead of $25 \mathrm{~mm}$ as the other two series of study A. ${ }^{\mathrm{b}}$ Set with boundary conditions as in study A. ${ }^{\mathrm{c}}$ For two specimens of this set, it was difficult to establish if the failure mode was mode 2 or 3 . The results without parenthesis refer to the case of six results of failure mode 2 and two results of failure mode 3 , while the results in parenthesis refer to the case of eight results of failure mode 2.

the entire width, $b$. The problem considered in Caprolu et al. [18] is reduced to determination and differentiation of the compliance of a simple cantilever beam with depth $h_{e}$, width $b$, and length $a$, where $a$ is the crack length. The compliance of such a cantilever beam, if taking flexural as well as shear deformations into account, is given by

$$
C(a)=\frac{4}{E b}\left(\frac{a}{h_{e}}\right)^{3}+\frac{\beta_{s}}{G b} \frac{a}{h_{e}},
$$

where $E$ is the modulus of elasticity, $G$ is the shear modulus, $h_{e}$ is shown in Figure 5, and $\beta_{s}$ is the shear correction factor (usually $6 / 5$ for a rectangular cross section). $E$ and $G$ are the appropriate values for the perpendicular-to-grain direction. It may here be noted that timber has different properties in the tangential and radial directions. This fact may be taken properly into account when using numerical methods like the Finite Element Method (see, e.g., Vessby et al. [32]) but is difficult to handle in simple analytical models. It is further for practical applications usually not possible to know with certainty how the timber is cut and oriented in the structure. It is thus often in analytical models for simplicity assumed that the timber has the same properties in the radial and tangential directions. This assumption will also be applied here.

Using (1) with $A=b a$ and the compliance as given by (2), the following expression for the failure load is obtained:

$$
P_{u}=b \sqrt{\frac{2 G \mathscr{G}_{f} h_{e}}{12(G / E)\left(a / h_{e}\right)^{2}+\beta_{s}}} .
$$

It is noted that the solution does not depend on the total depth, $h$, of the bottom rail.

Assuming small crack length $(a \rightarrow 0)$ or assuming that bending deformations can be ignored as compared with the shear deformations (i.e., $G / E \rightarrow 0$ ) leads to

$$
P_{u}=b \sqrt{\frac{2 G \mathscr{G}_{f} h_{e}}{\beta_{s}}} .
$$


TABLE 3: Results from testing of specimens with the pith oriented downwards (PD). Failure modes are defined in Figure 2.

(a) Study A

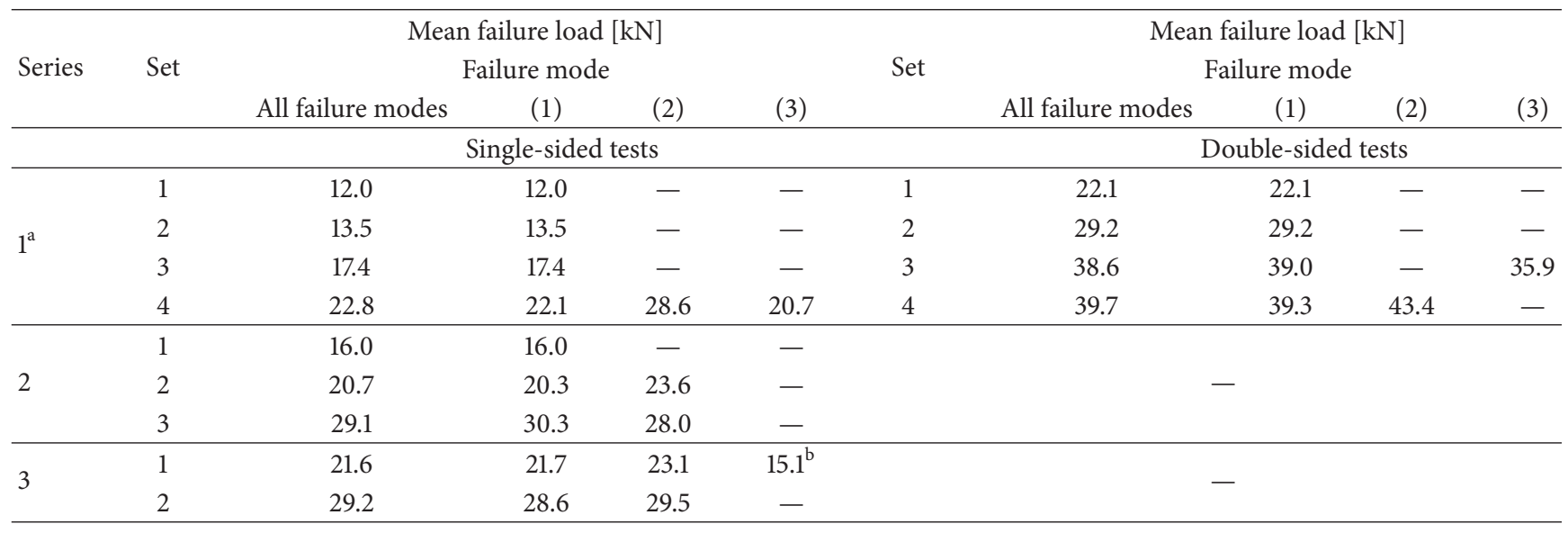

(b) Study B

\begin{tabular}{|c|c|c|c|c|c|c|c|c|c|c|}
\hline \multirow{3}{*}{ Series } & \multicolumn{5}{|c|}{ Mean failure load [kN] } & \multicolumn{5}{|c|}{ Mean failure load [kN] } \\
\hline & \multirow[t]{2}{*}{ Set } & \multicolumn{4}{|c|}{ Failure mode } & \multirow[t]{2}{*}{ Set } & \multicolumn{4}{|c|}{ Failure mode } \\
\hline & & All failure modes & $(1)$ & $(2)$ & (3) & & All failure modes & $(1)$ & $(2)$ & $(3)$ \\
\hline & \multicolumn{5}{|c|}{ Single-sided tests } & & \multicolumn{4}{|c|}{ Double-sided tests } \\
\hline & & & - & & & $1-B C(A)^{c}$ & 22.6 & 22.6 & - & - \\
\hline \multirow{4}{*}{1} & 1 & 10.3 & 10.2 & - & - & 1 & 20.5 & 20.5 & - & - \\
\hline & 2 & 13.5 & 13.5 & - & - & 2 & 28.0 & 28.0 & - & - \\
\hline & 3 & 18.2 & 17.9 & 16.7 & 19.0 & 3 & 39.1 & 39.5 & 38.0 & - \\
\hline & 4 & 21.8 & 23.5 & 20.7 & 21.4 & 4 & 45.8 & 45.4 & 47.1 & 44.2 \\
\hline \multirow{3}{*}{2} & 1 & 14.0 & 14.0 & - & - & & \multirow{3}{*}{-} & & & \\
\hline & 2 & 17.9 & 19.3 & $7.70^{\mathrm{d}}$ & - & & & & & \\
\hline & 3 & 23.7 & 23.5 & 25.6 & 21.3 & & & & & \\
\hline \multirow{2}{*}{3} & 1 & 18.1 & 15.9 & 19.5 & 19.4 & & \multirow{2}{*}{ - } & & & \\
\hline & 2 & 23.8 & - & 25.4 & 22.1 & & & & & \\
\hline
\end{tabular}

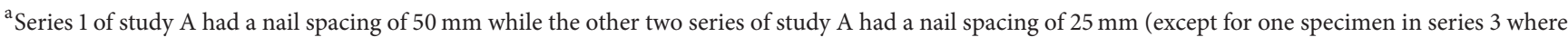
the spacing by mistake was $50 \mathrm{~mm}$ ). ${ }^{\mathrm{b}}$ This specimen had by mistake a nail spacing of $50 \mathrm{~mm}$ instead of $25 \mathrm{~mm}$, which is the reason for the ductile failure. ${ }^{\mathrm{c}}$ Set with boundary conditions as in study A. ${ }^{\mathrm{d}}$ Exceptionally low failure load, cause unknown.

Equations (3)-(4) are the same solutions as derived in Caprolu et al. [18].

3.1.2. Model 2. In Gustafsson [33], splitting failure of an endnotched beam as shown in Figure 6 is considered.

While the model presented in Caprolu et al. [18] assumes that only shear and bending deformations of the cantilever beam shown in Figure 5 give contributions to the compliance, the model derived in Gustafsson [33] also takes into account contributions from the part of the beam with depth $h$ and from additional rotation of the cantilever due to the fact that the stiffness of the beam with depth $h$ cannot be fully activated in the immediate vicinity of the corner of the notch. The solution given in Gustafsson [33] reads as follows:

$$
P_{u}=b \alpha h \frac{\sqrt{G \mathscr{G}_{f} / h}}{\sqrt{(3 / 5) \alpha(1-\alpha)}+\beta \sqrt{6(G / E)\left(1 / \alpha-\alpha^{2}\right)}},
$$

where $\alpha$ and $\beta$ are defined in Figure 6. It should be noted that (5) is based on (1) and the compliance is determined using simple beam theory and assuming the shear correction factor $\beta_{s}=6 / 5$.

Using (5) on a bottom rail as considered in Figure 5, ( $\beta$ h is then the crack length, $a$ ) the following failure load is obtained:

$$
\begin{array}{r}
P_{u}=b h \quad \\
\cdot \frac{\sqrt{G \mathscr{G}_{f} / h}}{\sqrt{(3 / 5)((1-\alpha) / \alpha)}+(a / h) \sqrt{6(G / E)\left(1 / \alpha^{3}-1\right)}}, \\
\alpha=\frac{h_{e}}{h} .
\end{array}
$$

It is noted that (6) takes into account the effect of the total depth, $h$, of the rail. 

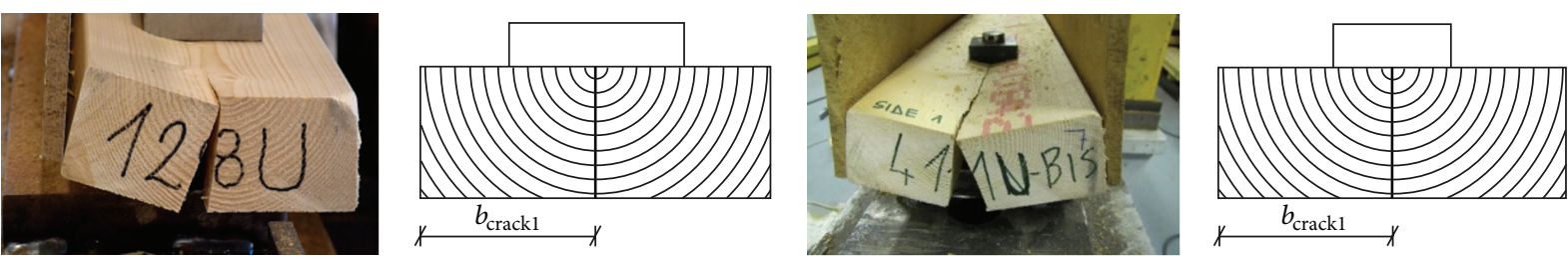

(a)
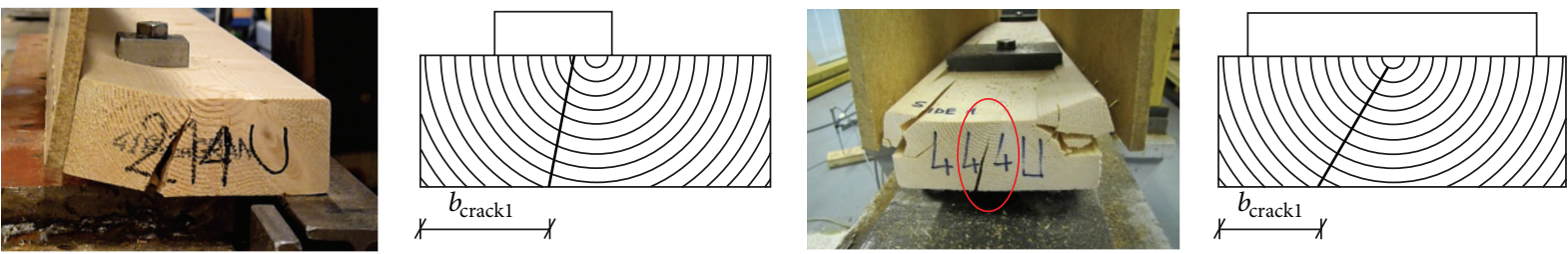

(b)
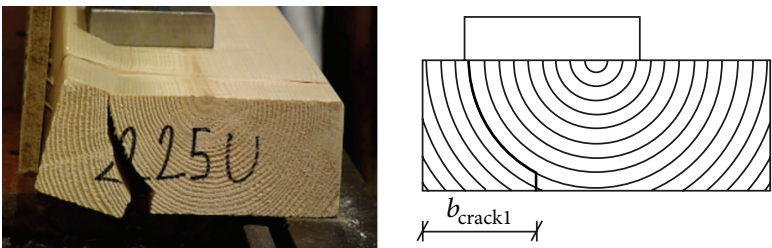

$b_{\text {crack } 1}, x$

(c)
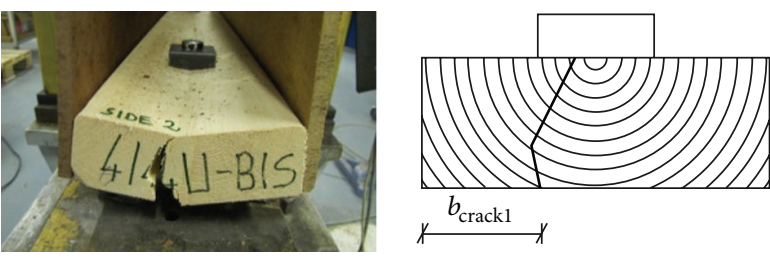

(d)
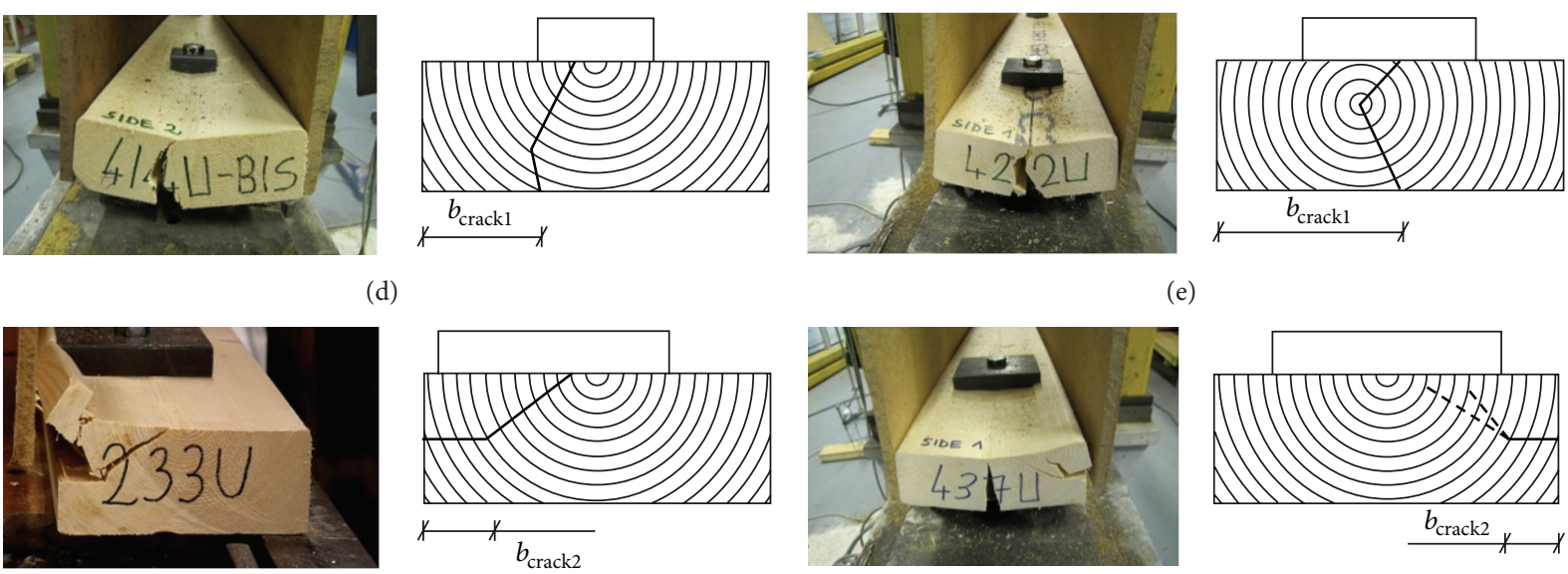

(e)
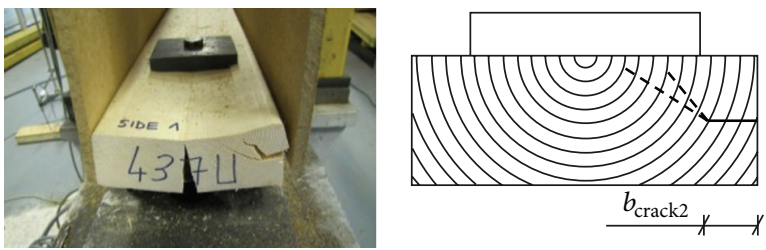

(f)
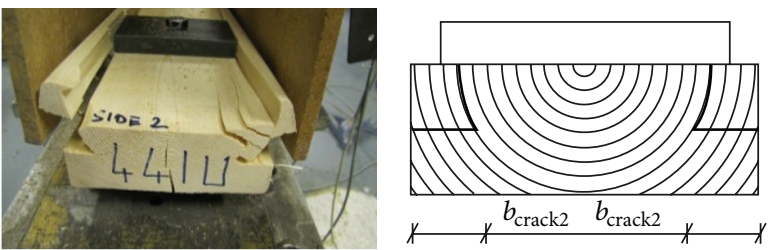

$(\mathrm{g})$

FIGURE 3: Crack development for bottom rail with pith oriented upwards (PU). (a) Mode 1 crack developing in a straight line, starting and propagating vertically at the centre of the bottom rail; (b) mode 1 crack developing in an oblique line initiating at the bottom surface of the bottom rail at a vertical position close to the edge of the washer and propagating towards the pith; (c) mode 1 crack developing in a straight line for a certain length and then following the annual rings; (d) mode 1 crack developing in an unusual direction, probably due to a weaker crack plane; (e) mode 1 crack developing towards the pith (pith in an unusual position); (f) mode 2 crack starting horizontally and then propagating vertically; and (g) mode 2 crack horizontally and then propagating vertically following the annual rings. 

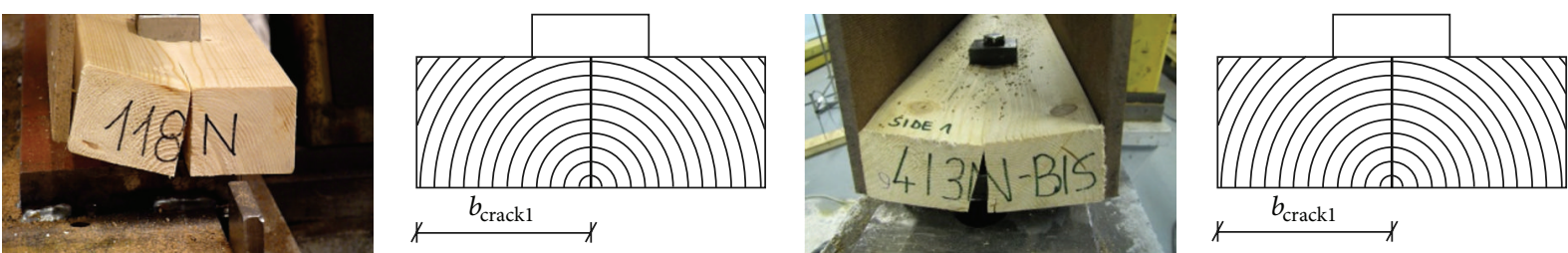

(a)
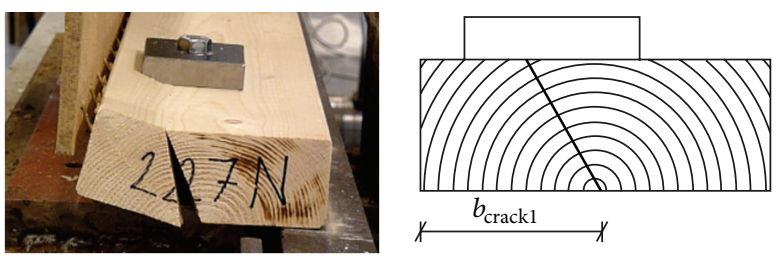

(b)
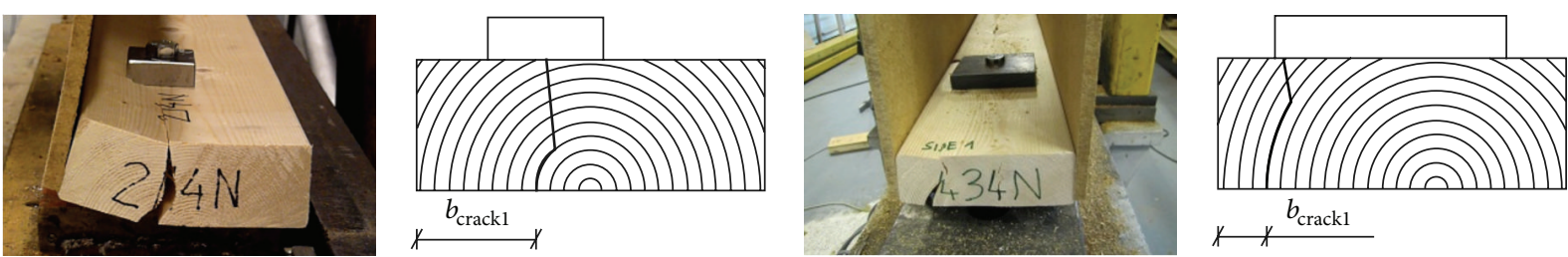

(c)
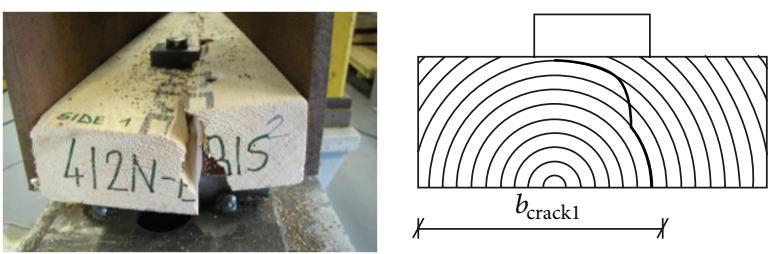

(d)
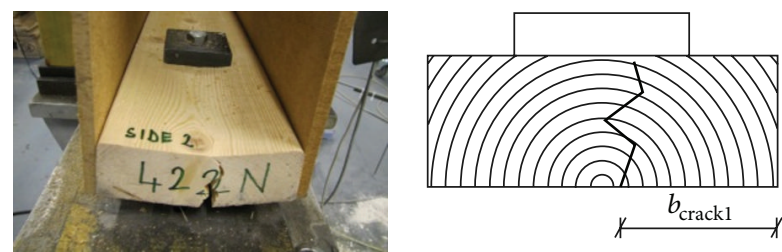

(e)
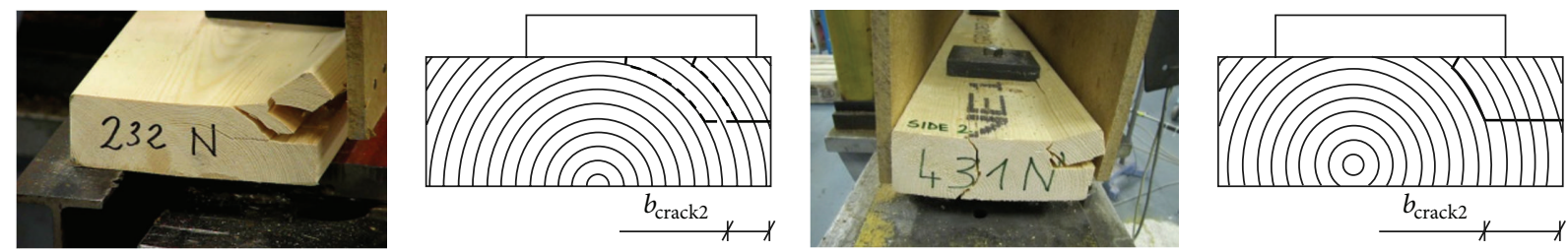

(f)

FIGURE 4: Crack development for bottom rail with pith oriented downwards (PD). (a) Mode 1 crack developing in a straight line starting and propagating vertically at the centre of the bottom rail; (b) mode 1 crack developing in an oblique line starting at a location close to the pith and propagating towards the loaded edge of the bottom rail; (c) mode 1 crack first following the annual rings and then propagating in a straight line towards the line of the anchor bolts; (d) mode 1 crack initiating off the centre on the bottom surface of the bottom rail and following an annual ring for a certain length and then jumping to another annual ring and propagating towards the centre of the upper surface of the bottom rail; (e) mode 1 crack propagating in an unusual "zig-zag" line across the annual rings; (f) mode 2 crack development, starting horizontally and then propagating vertically following the annual rings.

In the special case of a small crack $(a \rightarrow 0)$ or if assuming that the bending deformations are negligible as compared with the shear deformations $(G / E \rightarrow 0)$, (6) reduces to:

$$
P_{u}=b C_{1} \sqrt{\frac{h_{e}}{1-h_{e} / h}}, \quad C_{1}=\sqrt{\frac{5}{3} G \mathscr{G}_{f}} .
$$

Equation (7) leads to (4), for $h_{e} / h \rightarrow 0$.
3.1.3. Model 3. In Jensen [34], a beam loaded perpendicular to the grain by a bolt located close to the edge and close to the end of the beam was considered. Figure 7 defines the geometry.

Based on the theory for a Timoshenko-beam on a Winkler-foundation, a so-called quasi-nonlinear fracture mechanics solution was derived. The general expression for the failure load does not become simple, but for a small crack 


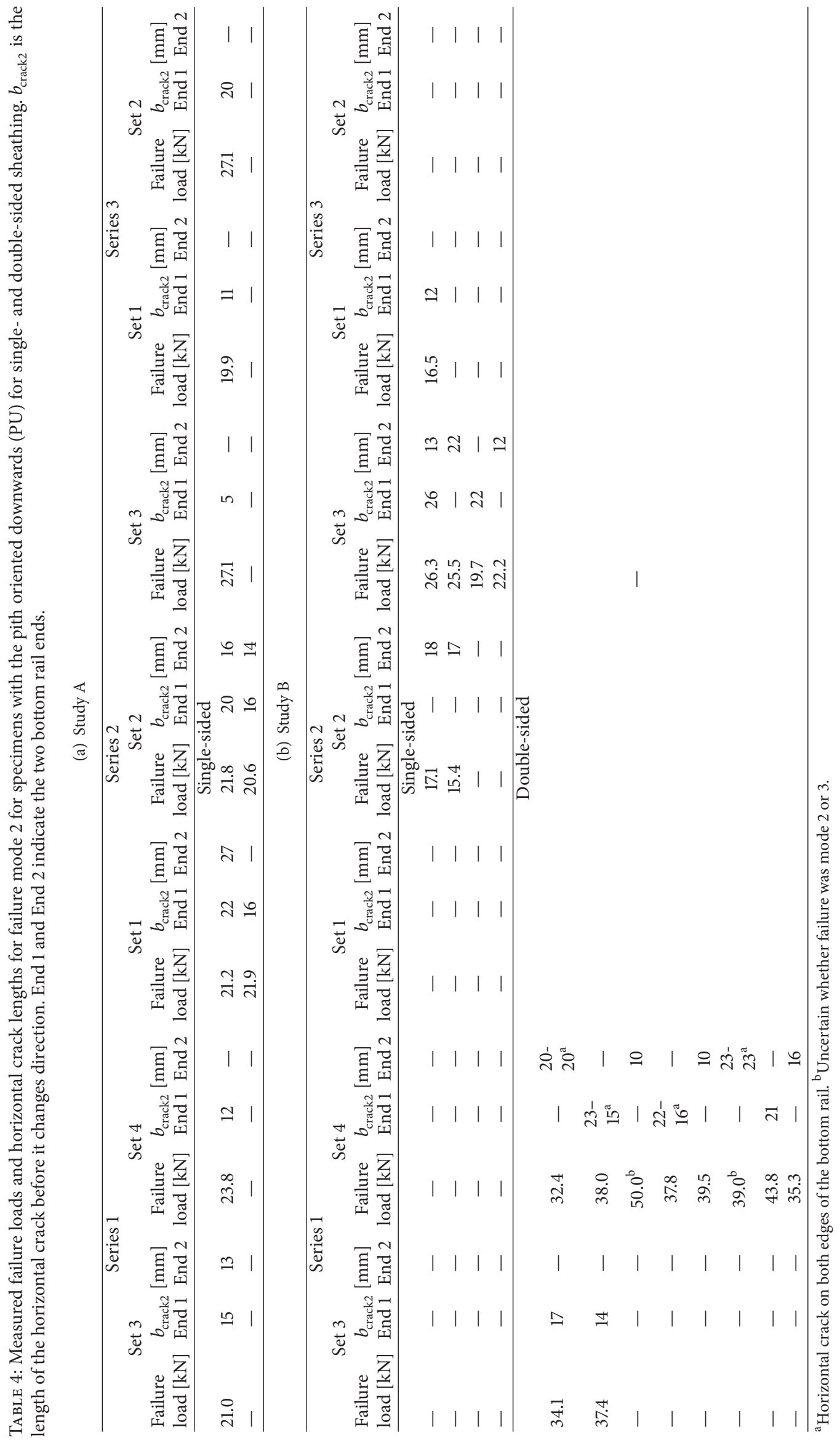




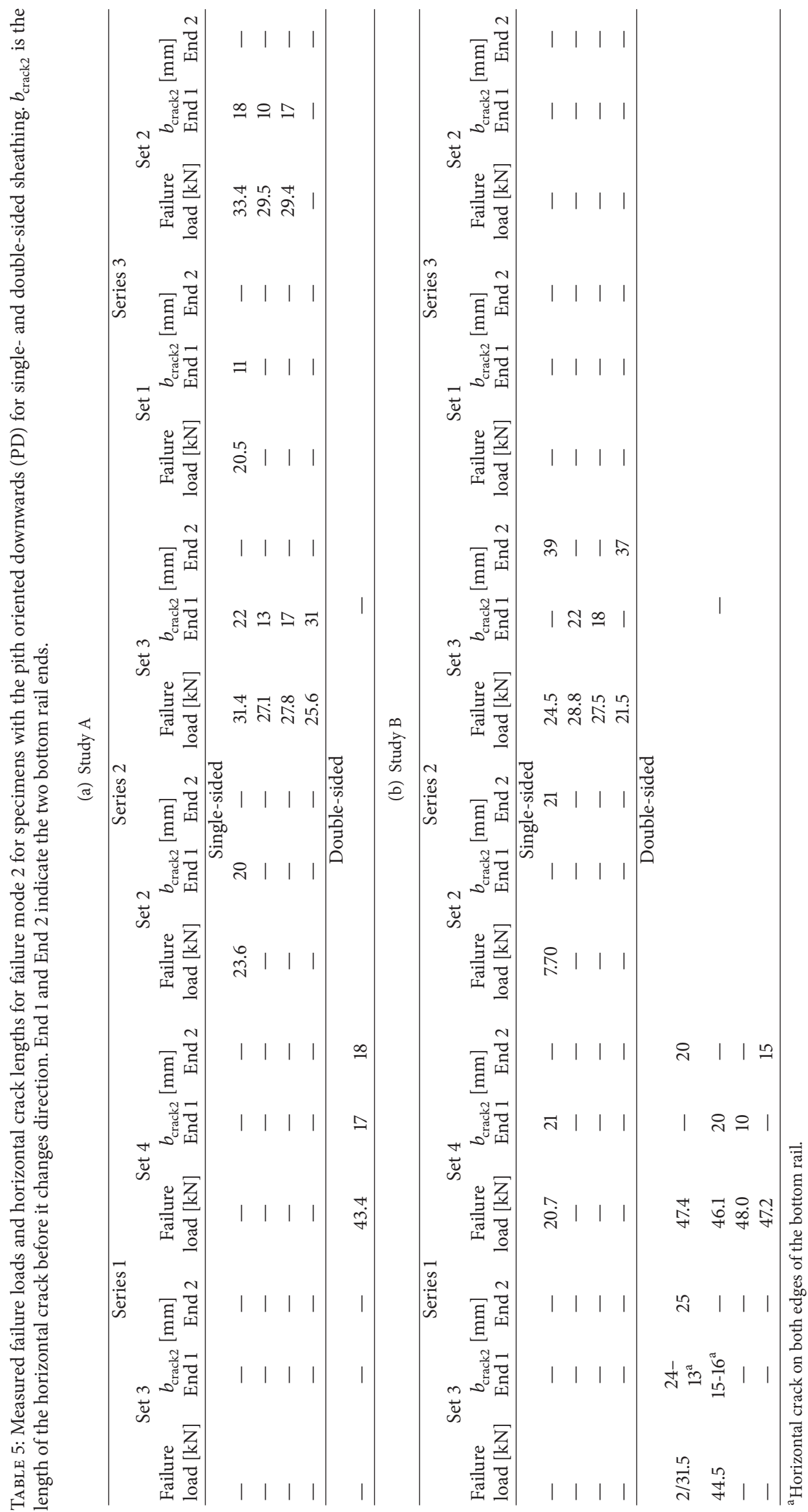



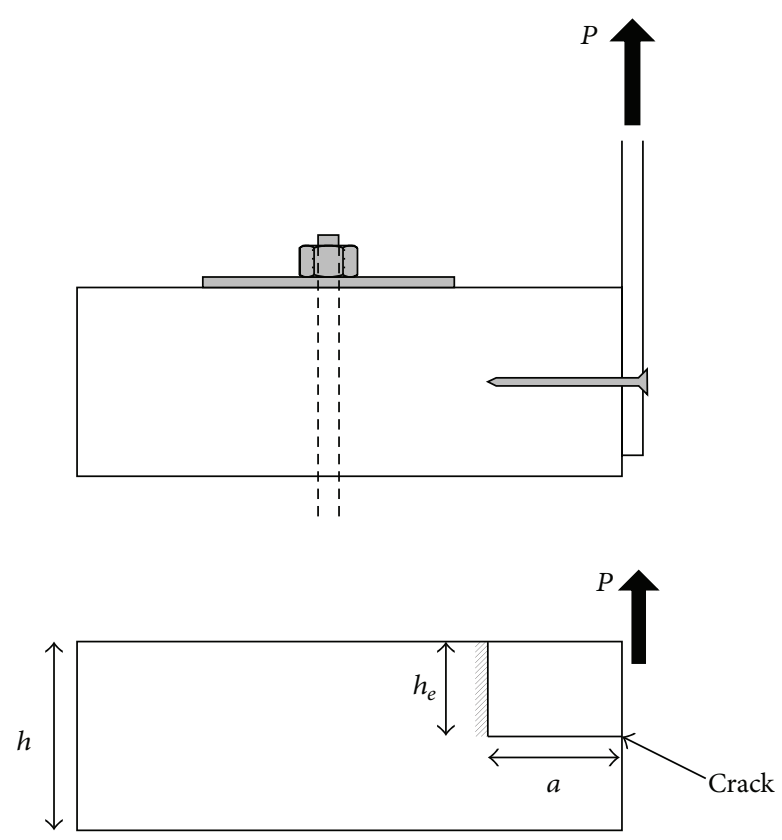

FIGURE 5: Geometry, boundary conditions, and loading conditions used in Caprolu et al. [18] for a horizontal crack.

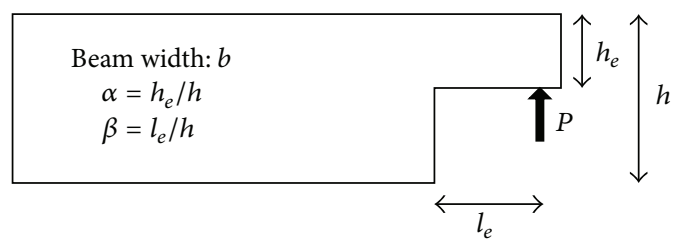

FIGURE 6: Geometry of end-notched beam as considered in Gustafsson [33].

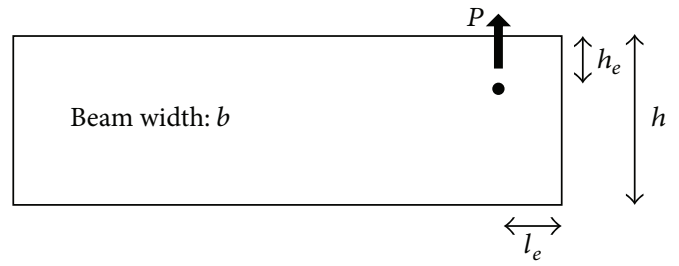

FIGURE 7: Geometry of beam considered in Jensen [34].

length $(a \rightarrow 0)$, the relatively simple solution given as (8) was obtained:

$$
\begin{gathered}
P_{u}=P_{0} \cdot \min \left\{\begin{array}{l}
\frac{1}{2 \sqrt{2 \zeta+1}}+\frac{b f_{t} l_{e}}{P_{0}} \\
\frac{\sqrt{2 \zeta+1}}{\zeta+1}
\end{array}\right. \\
P_{0}=2 b C_{1} \sqrt{h_{e}}, C_{1}=\sqrt{\frac{5}{3} G \mathscr{G}_{f}}, \zeta=\frac{C_{1}}{f_{t}} \sqrt{10 \frac{G}{E} \frac{1}{h_{e}}},
\end{gathered}
$$

where $f_{t}$ is the perpendicular-to-grain tensile strength.
The horizontal crack in a bottom rail may be considered a special case of (8), namely, for $l_{e} \rightarrow 0$, which leads to

$$
\begin{gathered}
P_{u}=P_{0} \frac{1}{2 \sqrt{2 \zeta+1}} \\
P_{0}=2 b C_{1} \sqrt{h_{e}}, C_{1}=\sqrt{\frac{5}{3} G \mathscr{G}_{f}}, \zeta=\frac{C_{1}}{f_{t}} \sqrt{10 \frac{G}{E} \frac{1}{h_{e}}} .
\end{gathered}
$$

It is noted that (9), for $f_{t} \rightarrow \infty$, leads to (4) if $\beta_{s}=6 / 5$.

In van der Put and Leijten [35], a linear elastic fracture mechanics model was derived for a simply supported beam loaded perpendicular to grain by a single-load at midspan. The solution given in (10) was obtained, where again $h$ is the beam depth and $h_{e}$ is the loaded edge distance:

$$
P_{u}=2 b C_{1} \sqrt{\frac{h_{e}}{1-h_{e} / h}}, \quad C_{1}=\sqrt{\frac{5}{3} G \mathscr{G}_{f}} .
$$

It is noted that (10) gives exactly twice the failure load as obtained from (7).

It is also noted that (10) for small edge distances $\left(h_{e} / h \rightarrow\right.$ 0 ) leads to $P_{u}=P_{0}$, where $P_{0}$ is given in (9). $P_{0}$ may therefore be regarded as a special case of (10). A semiempirical generalized version of (9) may be proposed:

$$
\begin{gathered}
P_{u}=\gamma b C_{1} \sqrt{\frac{h_{e}}{1-h_{e} / h}} \\
C_{1}=\sqrt{\frac{5}{3} G \mathscr{G}_{f}}, \gamma=\frac{1}{\sqrt{2 \zeta+1}}, \zeta=\frac{C_{1}}{f_{t}} \sqrt{10 \frac{G}{E} \frac{1}{h_{e}}} .
\end{gathered}
$$

Equation (11) then leads to (7), for $G / E \rightarrow 0$ or $f_{t} \rightarrow \infty$.

Equations (3)-(4) and (9) do not include the total depth of the bottom rail. This means that cracking is predicted also for situations, where the loaded edge distance is very close to the total depth of the bottom rail. Intuitively, the propensity to splitting should disappear in such situations since the part with depth $\left(h-h_{e}\right)$ has little stiffness as compared with the part with depth $h_{e}$ and thus offers little resistance against following the deflection of the part with depth $h_{e}$. Equations (6)-(7) and (11) take the effect of the total depth of the bottom rail into account and predict infinitely high failure loads for, $h_{e} / h \rightarrow 0$; that is, horizontal splitting is not an issue if the nails are placed sufficiently close to the bottom surface of the bottom rail.

\subsection{Vertical Cracking (Mode 1)}

3.2.1. Model 1. For a crack propagating vertically from the bottom surface of a bottom rail, Serrano et al. [19], Serrano et al. [17], and Caprolu et al. [18] consider a fully clamped beam as shown in Figure 8.

The problem is in Serrano et al. [17] again, as in the case of a horizontal crack, reduced to determination and differentiation of the compliance of a simple cantilever beam. Here is a cantilever beam with depth $(h-a)$, width $b$, and length $l_{e}$. The crack length is $a$; that is, the crack area again becomes $A=b a$. The compliance of such a cantilever beam, 


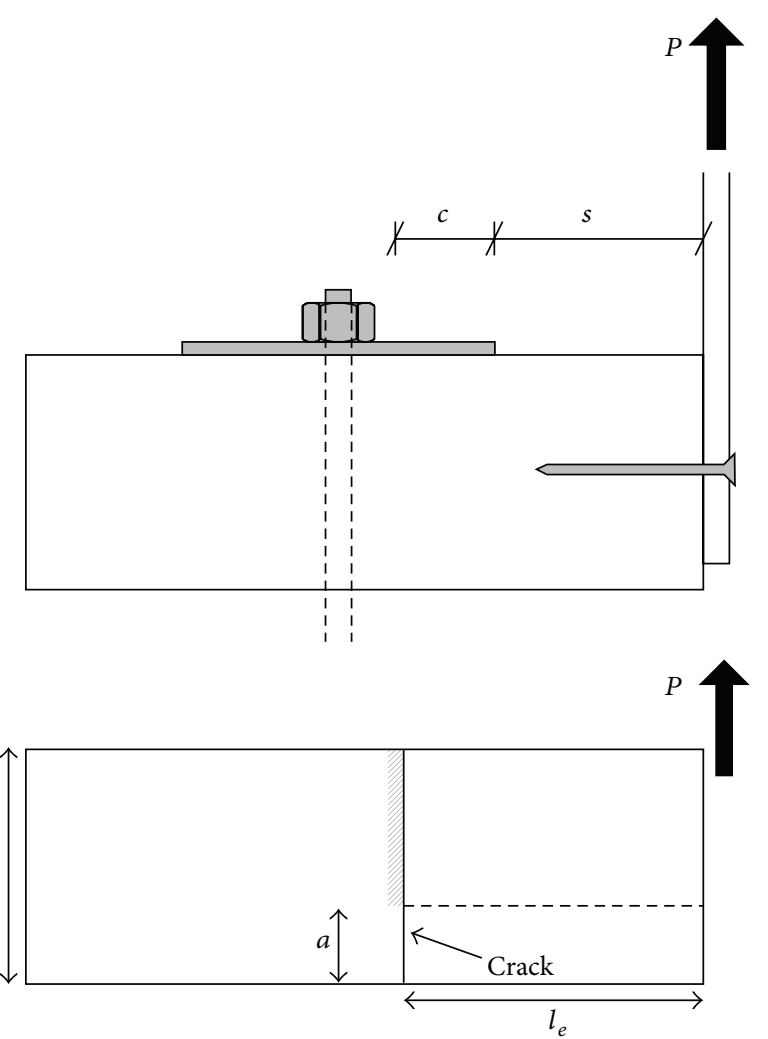

FIGURE 8: Geometry, boundary conditions, and loading conditions used in Serrano et al. [17] and in Caprolu et al. [18] for a vertical crack.

if taking flexural as well as shear deformations into account, is given by

$$
C(a)=\frac{4}{E b}\left(\frac{l_{e}}{h-a}\right)^{3}+\frac{\beta_{s}}{G b} \frac{l_{e}}{h-a}
$$

where $E$ is the modulus of elasticity, $G$ is the shear modulus, $\beta_{s}$ is the shear correction factor, and the geometry is given in Figure 8 .

It should be noted that the compliance as given by (12) is a conservative estimate since the part of the cantilever beam below the crack tip is not considered but in fact gives a contribution to the stiffness.

Using (1) with $A=b a$ and the compliance as given by (12), the following expression for the failure load is obtained:

$$
P_{u}=b(h-a) \sqrt{\frac{2 G \mathscr{G}_{f} / l_{e}}{12(G / E)\left(l_{e} /(h-a)\right)^{2}+\beta_{s}}} .
$$

Assuming a small crack length $(a \rightarrow 0)$ leads to

$$
P_{u}=b h \sqrt{\frac{2 G \mathscr{G}_{f} / l_{e}}{12(G / E)\left(l_{e} / h\right)^{2}+\beta_{s}}} .
$$

Assuming that bending deformations can be ignored $(G$ / $E \rightarrow 0$ ), (13) leads to

$$
P_{u}=b(h-a) \sqrt{\frac{2 G \mathscr{G}_{f}}{l_{e} \beta_{s}}} .
$$

Assuming the small crack length and that bending deformations can be ignored leads to

$$
P_{u}=b h \sqrt{\frac{2 G \mathscr{G}_{f}}{l_{e} \beta_{s}}} .
$$

3.2.2. Model 2. The cantilever beam as shown in Figure 8 is considered again. However, it is here assumed that the cantilever is not completely rigidly clamped at the end, but a finite rotation occurs. The deflection of the loading point, $\delta$, is then given by

$$
\delta=\delta_{b}+\delta_{v}+\delta_{r}
$$

where $\delta_{b}$ is the contribution from bending of the cantilever, $\delta_{v}$ is the contribution from shear of the cantilever, and $\delta_{r}$ is the contribution from a rotation at the clamped end of the cantilever. The rotation at the clamped end of the cantilever may be thought of as a simple linear elastic rotational spring with compliance $c_{r}$, and the deflection due to the rotation is then given by

$$
\delta_{r}=P l_{e}^{2} c_{r}
$$

where $c_{r}$ in general is a function of the crack length, $a$.

The compliance due to bending and shear is again given by (12), and the total compliance thus becomes

$$
C(a)=\frac{4}{E b}\left(\frac{l_{e}}{h-a}\right)^{3}+\frac{\beta_{s}}{G b} \frac{l_{e}}{h-a}+l_{e}^{2} c_{r} \text {. }
$$

Differentiation of $C(a)$ with respect to $a$ and use of (1) leads to

$$
\begin{aligned}
P_{u} & =b(h-a) \\
& \cdot \sqrt{\frac{2 G G_{f} / l_{e}}{12(G / E)\left(l_{e} /(h-a)\right)^{2}+b G l_{e}(h-a)^{2}\left(d c_{r}(a) / d a\right)+\beta_{s}}} .
\end{aligned}
$$

If the following choice is made for the spring compliance,

$$
c_{r}=\frac{1}{b} \sqrt{12 \frac{\beta_{s}}{G E}} \frac{1}{(h-a)^{2}} .
$$

A particularly simple expression is obtained for the failure load, namely,

$$
P_{u}=b(h-a) \frac{\sqrt{2 G \mathscr{G}_{f} / l_{e}}}{\sqrt{12(G / E)}\left(l_{e} /(h-a)\right)+\sqrt{\beta_{s}}} .
$$

The similarity/difference between (22) and (13) is noted. 
For a small crack length, (22) gives

$$
P_{u}=b h \frac{\sqrt{2 G \mathscr{G}_{f} / l_{e}}}{\sqrt{12(G / E)}\left(l_{e} / h\right)+\sqrt{\beta_{s}}} .
$$

Assuming negligible bending deformations, (22) leads to

$$
P_{u}=b(h-a) \sqrt{\frac{2 G \mathscr{G}_{f}}{l_{e} \beta_{s}}} .
$$

And both small crack length and insignificant bending deformations lead to

$$
P_{u}=b h \sqrt{\frac{2 G \mathscr{G}_{f}}{l_{e} \beta_{s}}} .
$$
(16).

Equation (24) is the same as (15), and (25) is the same as

3.2.3. Model 3. In the derivation of the end-notched beam model by Gustafsson [33], the cantilever has been assumed fixed to a rotational spring in exactly the same way as in model 2. However, in Gustafsson [33], the compliance, $c_{r}$, of the rotational spring was chosen as

$$
c_{r}=\frac{12}{b h^{2} \sqrt{10 G E}} \sqrt{\frac{(1-\alpha)\left(1-\alpha^{3}\right)}{\alpha^{4}}},
$$

where $\alpha=1-a / h$.

The compliance of the spring was also in Gustafsson [33] chosen so as to result in a simple expression for the failure load. However, since the crack propagation considered in Gustafsson [33] makes the length of the cantilever increase, while the crack considered here propagates so that the length of the cantilever is constant but its depth decreases, the influence of crack propagation becomes different in the two cases, and thus different expressions ((21) and (26)) for the spring compliance optimize the simplicity.

The spring compliance as given by (26) has been proven to give good results for end-notched beams. If (26) is used in (20), the following expression is obtained for the failure load:

$$
P_{u}=b \alpha h \sqrt{\frac{2 G \mathscr{G}_{f} / l_{e}}{12(G / E)\left(l_{e} / \alpha h\right)^{2}+\sqrt{(18 / 5)(G / E)}\left(\left(4-3 \alpha-\alpha^{3}\right) / \sqrt{(1-\alpha)\left(1-\alpha^{3}\right)}\right)\left(l_{e} / \alpha h\right)+\beta_{s}}} .
$$

For a small crack length, $\alpha \rightarrow 1$, and thus

$$
\begin{aligned}
& P_{u} \\
& =b h \sqrt{\frac{2 G \mathscr{G}_{f} / l_{e}}{12(G / E)\left(l_{e} / h\right)^{2}+6 \sqrt{(6 / 5)(G / E)}\left(l_{e} / h\right)+\beta_{s}}} .
\end{aligned}
$$

If the deformations from bending are assumed to be negligible as compared with the shear deformations, (27) gives

$$
P_{u}=b \alpha h \sqrt{\frac{2 G \mathscr{G}_{f}}{\beta_{s} l_{e}}} .
$$

And for small crack length and negligible bending deformations,

$$
P_{u}=b h \sqrt{\frac{2 G \mathscr{G}_{f}}{\beta_{s} l_{e}}} .
$$

Equation (29) is the same as (15) and (24), and (30) is the same as (16) and (25).

3.3. Additional Failure Modes and Modifications. Figure 2(c) shows a failure mode (mode 3 ) where the nails and/or the wood yield and the nails are pulled out of the bottom rail. This failure mode is treated in Caprolu et al. [18] and is outside the scope of the present paper, which focuses on failure of the bottom rail. The models presented in Sections 3.1 and 3.2 consider horizontal and vertical crack propagation, respectively. However, in addition to crack propagation, bending and shear failures of the considered cantilever beams may also occur and cause failure of the bottom rail. Here simplified models will be used.

For horizontal crack propagation (mode 2), the following equations should also be considered for bending and shear, respectively:

$$
\begin{aligned}
& P_{u}=\frac{b h_{e}^{2}}{6 a} f_{t} \\
& P_{u}=\frac{2}{3} b h_{e} f_{v},
\end{aligned}
$$

where $f_{t}$ is the perpendicular-to-grain tensile strength, and $f_{v}$ the rolling shear strength.

For vertical crack propagation (mode 1), the following equations for bending and shear should be considered in addition to the fracture mechanics models:

$$
\begin{aligned}
& P_{u}=\frac{b(h-a)^{2}}{6 l_{e}} f_{t} \\
& P_{u}=\frac{2}{3} b(h-a) f_{v} .
\end{aligned}
$$

The failure load of the bottom rail subjected to uplift is the minimum value of the failure loads given by (31)-(34) and 
two selected models (one for horizontal cracking and one for vertical cracking) from Sections 3.1 and 3.2.

The fracture mechanics models considered in Sections 3.1 and 3.2 are all based on (1) and consider an existing crack of length $a$. All the derived models predict that the load needed to propagate the crack decreases with increasing crack length, and the maximum load which the bottom rail can sustain is thus obtained from the models by assuming zero crack length. However, it may be relevant to assume a certain minimum or critical value, $a_{c}$, of the crack length as suggested in Serrano and Gustafsson [30]:

$$
a_{c}=\frac{E_{90} \mathscr{G}_{f}}{\pi f_{t}^{2}},
$$

where $E_{90}$ is the modulus of elasticity in the perpendicularto-grain direction. Different values of the material properties may be used in (35) for the tangential and radial directions if such distinction is made.

In Caprolu et al. [18], (35) was considered together with the models presented in Section 3.1.1 for a horizontally propagating crack (mode 2) and in Section 3.2.1 for a vertically propagating crack (mode 1 ). The length, $l_{e}$, of the cantilever beam considered in Section 3.2 was introduced as $l_{e}=s+$ $c$ as shown in Figure 8, where $s$ is the distance from the loaded edge of the bottom rail to the edge of the washer and $c$ is an additional length in recognition of the fact that the bottom rail may not be fully clamped at the edge of the washer. From (3) and (13), theoretical expressions, $l_{e 0}$, were given for the value of $l_{e}$ which determines the limit between vertical crack propagation (mode 1) and horizontal crack propagation (mode 2 ) for general orthotropic conditions and inclusion of (35). For the special case of isotropic conditions (assuming the same material properties in the radial and tangential directions) and assuming zero initial crack length, they determined the limit to

$$
\begin{aligned}
l_{e 0}= & \sqrt[3]{\frac{\beta_{s} E h^{4}}{24 G h_{e}}+\sqrt{\left(\frac{\beta_{s} E h^{4}}{24 G h_{e}}\right)^{2}+\left(\frac{\beta_{s} E h^{2}}{24 G}\right)^{3}}} \\
& +\sqrt[3]{\frac{\beta_{s} E h^{4}}{24 G h_{e}}-\sqrt{\left(\frac{\beta_{s} E h^{4}}{24 G h_{e}}\right)^{2}+\left(\frac{\beta_{s} E h^{2}}{24 G}\right)^{3}}} .
\end{aligned}
$$

A horizontally propagating crack (mode 2 ) leads to failure of the bottom rail if $l_{e}<l_{e 0}$ and a vertically propagating crack (mode 1) leads to failure if $l_{e}>l_{e 0}$.

Further, in Caprolu et al. [18] $c$ was estimated from experimental data by fitting using (13).

\section{Discussion}

While the crack path is predetermined for problems such as end-notched beams or splitting of beams loaded perpendicular to grain by bolted connections where the crack propagates along the grain, this is not the case in a bottom rail as considered here. The models presented in Sections 3.1

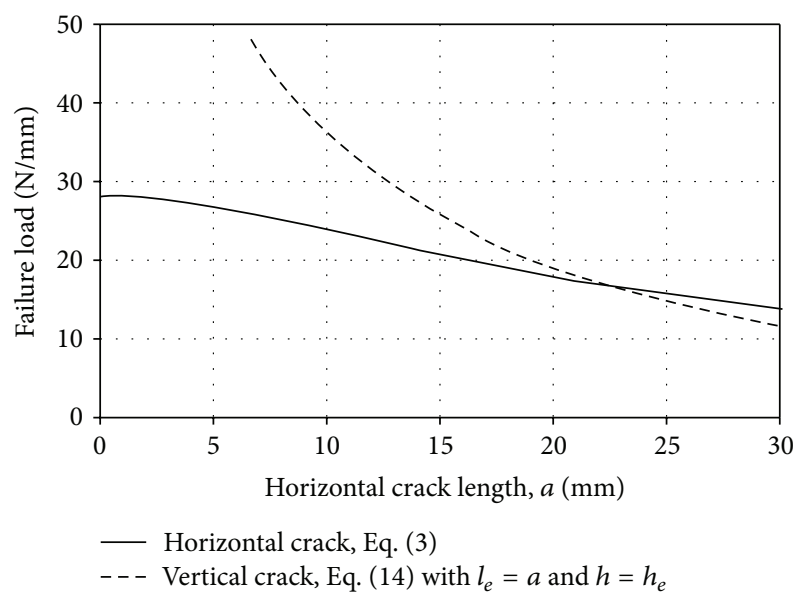

FIGURE 9: Example of propagation of initial horizontal crack in bottom rail and possible change to vertical propagation.

and 3.2 assume that the crack propagates either horizontally or vertically, but it is in fact very likely that the direction of the crack propagation changes as the crack grows. For instance, at any stage of the propagation of a horizontal crack as considered in Section 3.1, the crack may change direction and start propagating vertically (as considered in Section 3.2) if this requires less energy.

For simplicity, consider the simplest models for horizontal and vertical crack propagation, that is, the models given in Sections 3.1.1 and 3.2.1 and first presented in Serrano et al. [19] and Caprolu et al. [18]. Assume that a horizontal crack has been initiated and grown to the length, $a$, as shown in Figure 5. At what length will the crack start to grow vertically (if at all at any crack length)? The solution is given by taking (3) as it is and setting it equal to (14), in which $l_{e}=a$ and $h=h_{e}$. These equations lead to the solution that the crack will start propagating in the vertical direction when $a=h_{e}$. Figure 9 illustrates the problem. According to (3), the horizontal crack will propagate at decreasing load levels until $a=h_{e}$, then the crack will start propagating vertically. Figure 9 shows the failure load per $\mathrm{mm}$ of the length of the bottom rail given as a function of the horizontal crack length, $a$, using $h=45 \mathrm{~mm}, h_{e}=22.5 \mathrm{~mm}, E=400 \mathrm{MPa}, G=$ $70 \mathrm{MPa}, \mathscr{G}_{f}=0.30 \mathrm{~N} / \mathrm{mm}$, and $\beta_{s}=6 / 5$. The material properties are those used in Serrano et al. [19] and Caprolu et al. [18]. Using (3) and (14), the point where the horizontal crack starts propagating vertically is $a=h_{e}$ and is independent of the geometry and material properties of the bottom rail. The same exercise may be done using other models for the horizontal and vertical crack propagation, but an explicit expression can in general not be given for the point, where the horizontal crack starts propagating vertically.

In Serrano et al. [19] and Caprolu et al. [18], the perpendicular-to-grain tensile strength is assumed to be $f_{t}=$ $2.5 \mathrm{MPa}$. If further assuming the (rolling) shear strength $f_{v}=$ $3 \mathrm{MPa}$, inclusion of (31)-(32) leads to Figure 10 for the initially horizontally propagating crack also considered in Figure 9.

According to Figure 10, the horizontal crack will propagate to a length of $8.5 \mathrm{~mm}$, and then bending failure will occur in the cantilever as given by (31). 


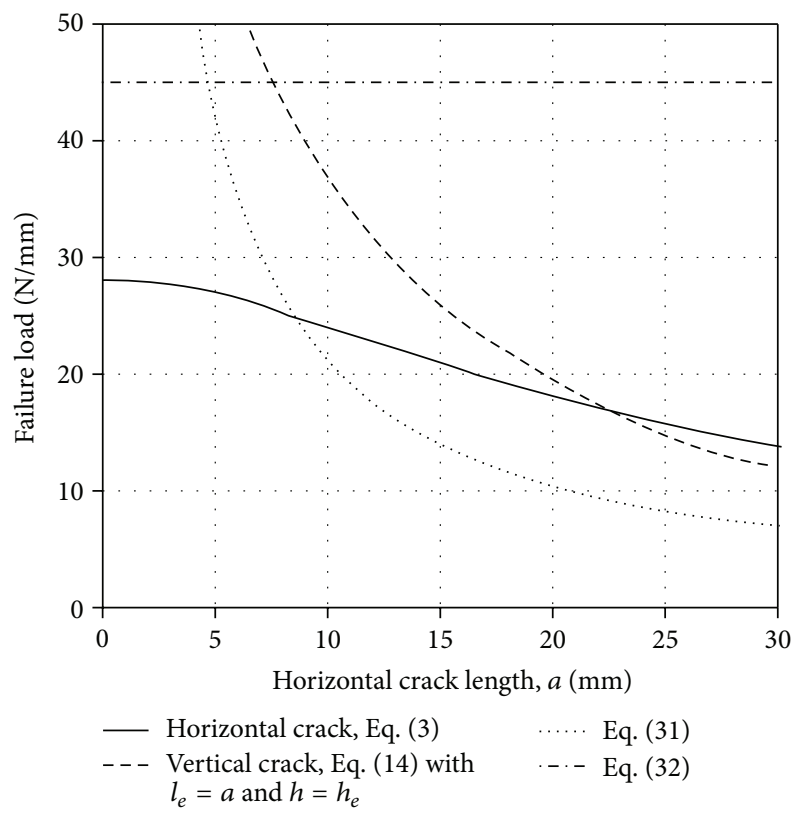

FIGURE 10: Example of propagation of horizontal crack including possible bending and shear failure modes and change of crack propagation direction.

If the perpendicular-to-grain tensile strength is assumed to be $f_{t}=4.5 \mathrm{MPa}$ (instead of $2.5 \mathrm{MPa}$ ), then (31) leads to a curve very close to the curve corresponding to the vertical crack in Figure 10 and intersects with the horizontal crack curve at $a=22.5 \mathrm{~mm}$ (for experimental results and discussion on the tensile strength value, see, e.g., Gustafsson [28], Boström [36], Holmberg [37], and Siimes [38]). The perpendicular-to-grain tensile strength of wood is always a debatable property partly due to the fact that different testing standards may lead to significantly different values, partly due to the fact that the strength is volume dependent. For a more detailed discussion, see the appendix.

In the experimental programs, the length of the horizontal part of the crack before it changes direction has been measured for some of the specimens and is given in Tables 4 and 5. The crack lengths were measured on the ends of the bottom rail as illustrated in Figure 11 for specimens with single- and double-sided sheathing.

All test specimens had bottom rails with $h=45 \mathrm{~mm}$ and $h_{e}=22.5 \mathrm{~mm}$. Accordingly, (3) and (14) predict that the crack will change to propagating in the vertical direction after having propagated $22.5 \mathrm{~mm}$ horizontally. Though the measured figures given in Tables 4 and 5 are roughly in agreement with this prediction, the experimental results are too scarce and the variation is too large to make any firm conclusions about agreement between theory and experiments. Further, as illustrated in Figure 10, the change of direction of the crack may not only be due to vertical crack propagation, but also due to bending failure of the cantilever beam considered in the models. The perpendicular-to-grain tensile strength of wood is associated with significant variation, and, as illustrated in Figure 10, this may lead to significant variation in the length of the horizontal crack. It is further uncertain how much the washers influence the measured horizontal cracks. The influence of the washers is not considered in any of the models presented in Section 3.1 for horizontally propagating cracks. Finally, it should be noted that the fracture models presented are all idealized models, which, for example, assume that the load is applied as a point load at the edge of the bottom rail. In reality, the load on the bottom rail is transferred by the nails over a certain length in the horizontal direction. This may have some significant effects, which are not considered in the models.

It should, however, be noted that (14) for the vertical crack propagation and (31) for the bending failure of the cantilever predict infinitely high failure loads for an initially horizontal crack $a=0\left(l_{e}=0\right)$, and (3) and (32) will thus determine the failure load of the bottom rail for a horizontally propagating crack. For most practical applications, the shear failure will not be relevant either.

A crack, which starts propagating vertically at the bottom side of the rail, will usually not change direction and start propagating horizontally if the timber is considered homogeneous and isotropic (i.e., no distinction is made between radial and tangential directions). For real orthotropic and inhomogeneous materials, the crack may, however, follow different paths as exemplified by Figures 3(c) and 4(e). Figure 10 indicates that shear failure will usually not occur for horizontal cracks and is even more unlikely for vertical cracks. The failure of the rail in case of a vertically propagating crack is therefore realistically the minimum of vertical crack propagation and bending of the cantilever, that is, for instance, Min \{Equation (13); Equation (33)\}.

Figure 12 shows a vertical crack propagation using the material properties that apply to Figure 9 and three different values of $f_{t}(=2 \mathrm{MPa}, 3 \mathrm{MPa}$, or $4 \mathrm{MPa})$. Here the total depth of the bottom rail is assumed to be $45 \mathrm{~mm}$ and the vertical crack is assumed to initiate $45 \mathrm{~mm}$ from the loaded edge.

For the vertical crack, the bending capacity as given by (33) takes on a finite value for zero crack length and may thus overrule the fracture mechanics solution for crack propagation depending on the value of the perpendicularto-grain tensile strength. For the example considered in Figure 12, bending failure will occur if $f_{t}=3 \mathrm{MPa}$ or less; vertical crack propagation will occur if $f_{t}=4 \mathrm{MPa}$ or above.

Figure 12 also included (3) in the following form

$$
P_{u}=b \sqrt{\frac{2 G \mathscr{G}_{f} h_{e}}{12(G / E)\left(l_{e} / h_{e}\right)^{2}+\beta_{s}}},
$$

where $l_{e}$ is the distance from the loaded edge of the rail to the crack tip and $h_{e}=h-a, a$ being the distance of the crack tip above the bottom side of the rail. Equation (37) thus gives the load at which the crack will propagate horizontally at any stage of a vertically propagating crack.

The use of (3) and (13) for an initially assumed vertical crack at the bottom surface of the bottom rail leads to the fact that the crack will continue its vertical propagation if it initiates a distance $l_{e}>h$ from the loaded edge. Assuming $l_{e}<h$ leads to horizontal crack propagation until $l_{e}=h$, and then the crack will propagate vertically. Horizontal crack 


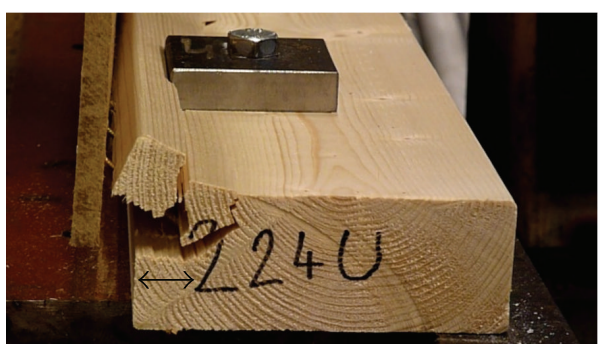

(a)

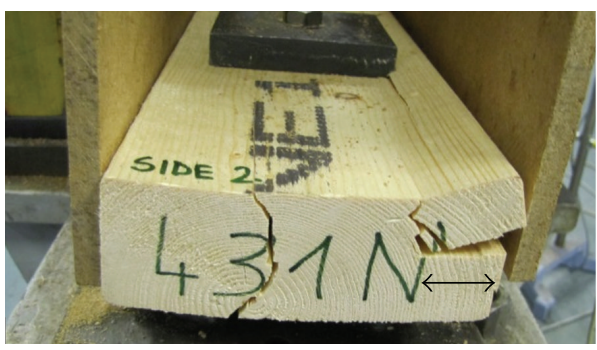

(c)

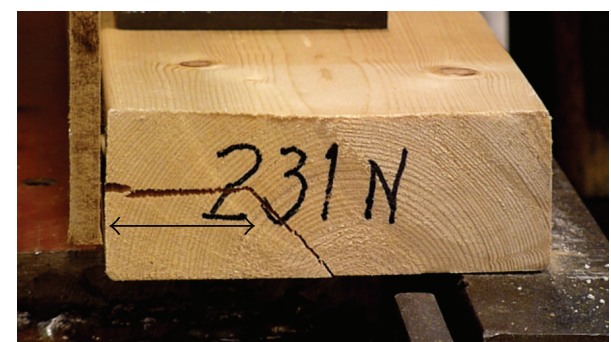

(b)

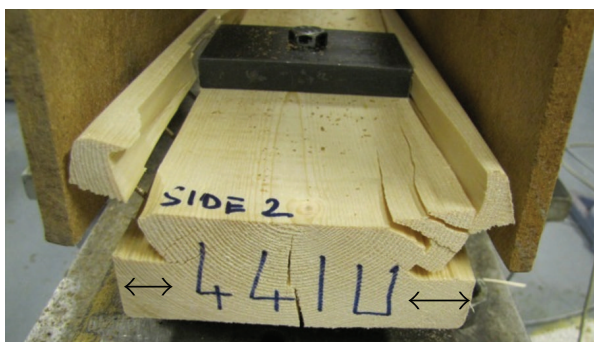

(d)

FIGURE 11: Examples of length of horizontally propagating cracks measured on the test specimens.

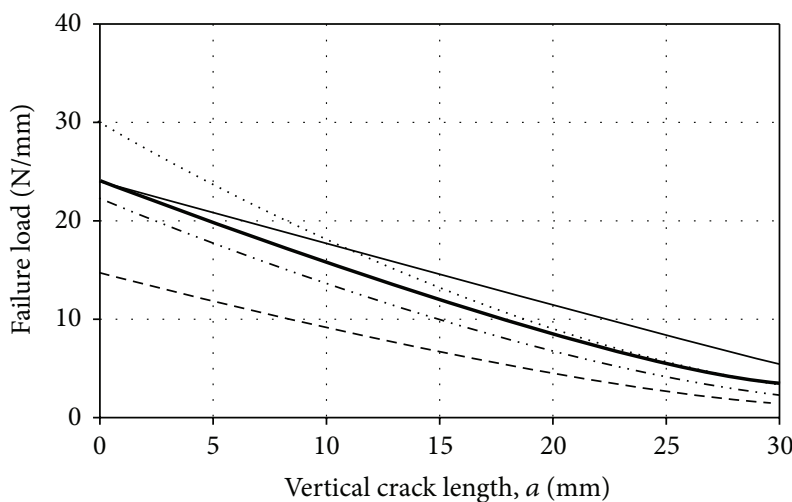

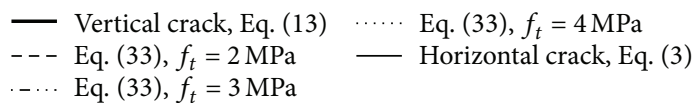

FIGURE 12: Example of propagation of vertical crack including possible bending failure and the possibility for the crack to change to propagation in the horizontal direction.

propagation along the bottom side of the rail is physically not meaningful but may be interpreted in the way that (3) and (13) exclude vertical crack initiation closer to the loaded edge than the depth of the rail. This prediction seems to be roughly in agreement with the experimental observations (Figures 3 and 4). However, the alternative models for horizontal crack propagation as presented in Sections 3.1.2 and 3.1.3 predict infinitely high failure loads for $h_{e}=h$; that is, a horizontal crack will not propagate near the bottom surface of the bottom rail.

In Figure 13, (14), (23), and (28), which correspond to Models 1, 2, and 3, respectively, are for vertical crack propagation (mode 1) compared with the experimental data.
Figure 13(a) refers to specimens with single-sided sheathing, while Figure 13(b) refers to specimens with double-sided sheathing. All three equations are based on the assumption that failure occurs for $a \rightarrow 0$. The following material properties were used: $h=45 \mathrm{~mm}, E=400 \mathrm{MPa}, G=70 \mathrm{MPa}$, $\mathscr{G}_{f}=0.30 \mathrm{~N} / \mathrm{mm}$, and $\beta_{s}=6 / 5$ (for experimental results on fracture energy values, see, e.g., Smith et al. [29], Reiterer et al. [39], and Larsen and Gustafsson [40]). The effective length, $l_{e}=s+c$, has been used with $c=20 \mathrm{~mm}$ which is roughly the value determined from the experimental data by minimization of the error using (13) and (35) as described in Caprolu et al. [18] for all specimens considered. The total load applied on the $900 \mathrm{~mm}$ long bottom rail is plotted as a function of the distance $s$. For double-sided sheathing, the theoretical expressions have been multiplied by two.

Equations (23) and (28) lead to better agreement with the experimental data than does (14). Equations (23) and (28) differ from (14) by taking into account an additional rotation of the cantilever at the clamped end. It may be argued that the additional contribution, $c$, to the length of the cantilever accounts for the same effect as the additional rotation and should not be included when using (23) and (28). However, since the washer only has a very limited extension in the length direction of the bottom rail, it is not reasonable to expect that any 2D model should result in perfect agreement with tests without some kind of empirical adjustment. Use of $l_{e}=s+c, c=20 \mathrm{~mm}$, seems to render very good results together with (23) and (28) though the value of $c$ has been optimized for use with (13).

Figure 14 compares (13) and (22) with the experimental results. Figure 14 (a) refers to specimens with singlesided sheathing, while Figure 14(b) refers to specimens with double-sided. Here the initial crack length as given by (35) has been used. The same material properties as used in Figure 13 


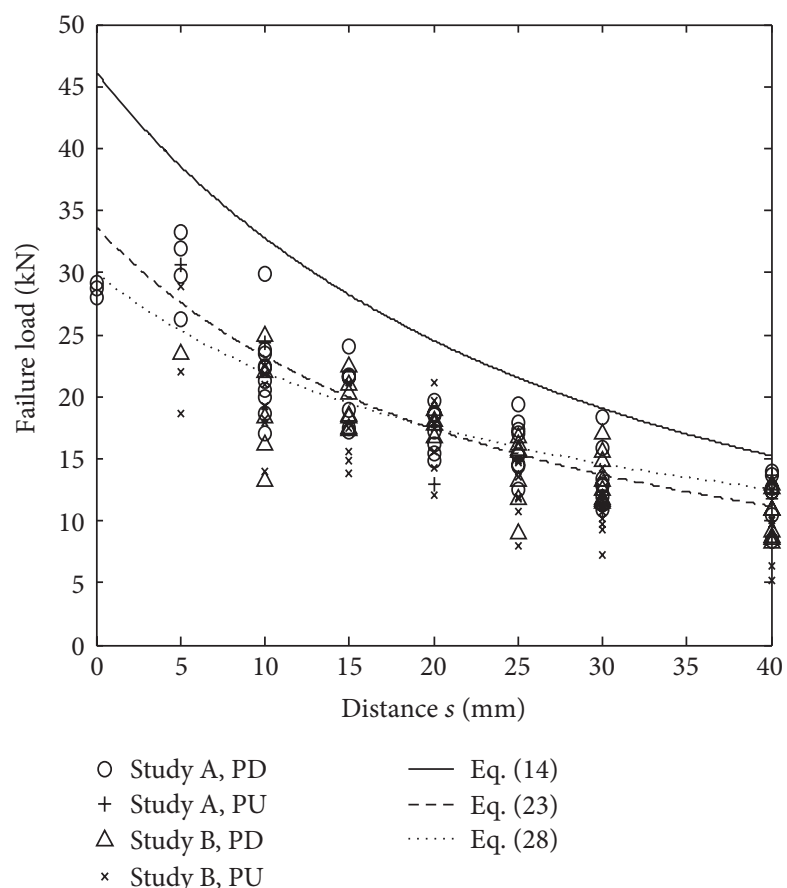

(a)

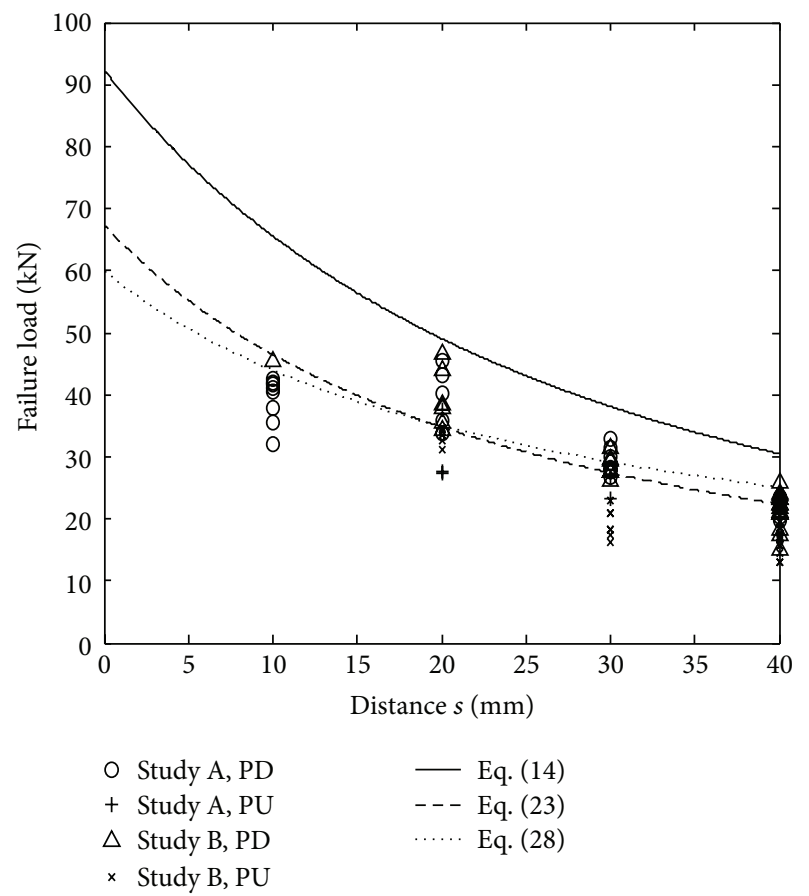

(b)

FIGURE 13: Comparison between theory and experiments for vertical cracking of a bottom rail assuming zero initial crack length. (a) Specimens with single-sided sheathing and (b) specimens with double-sided sheathing. PD = pith downwards, PU = pith upwards.

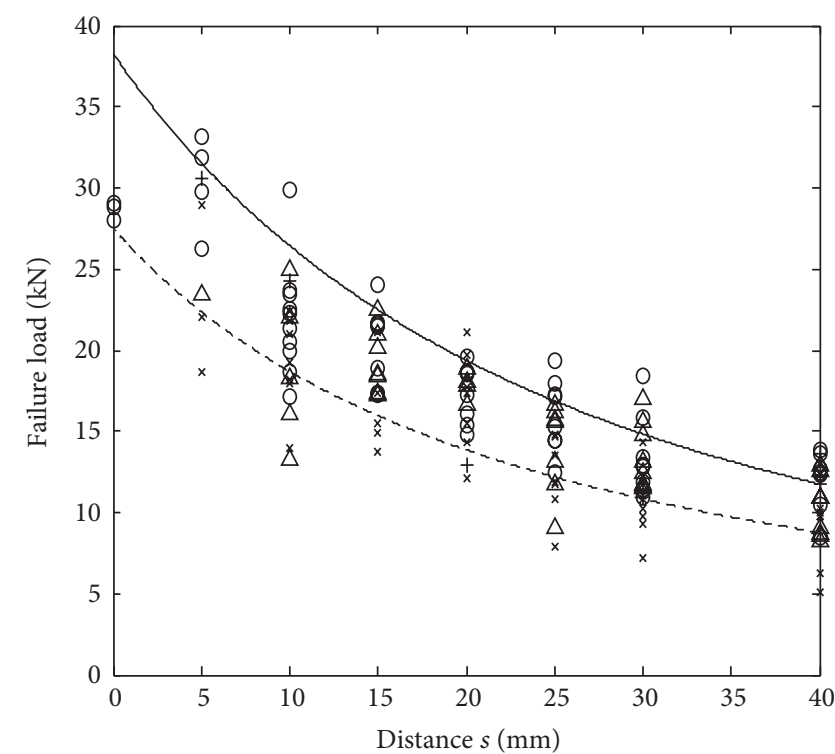

O Study A, PD

+ Study A, PU

$\triangle$ Study B, PD

× Study B, PU

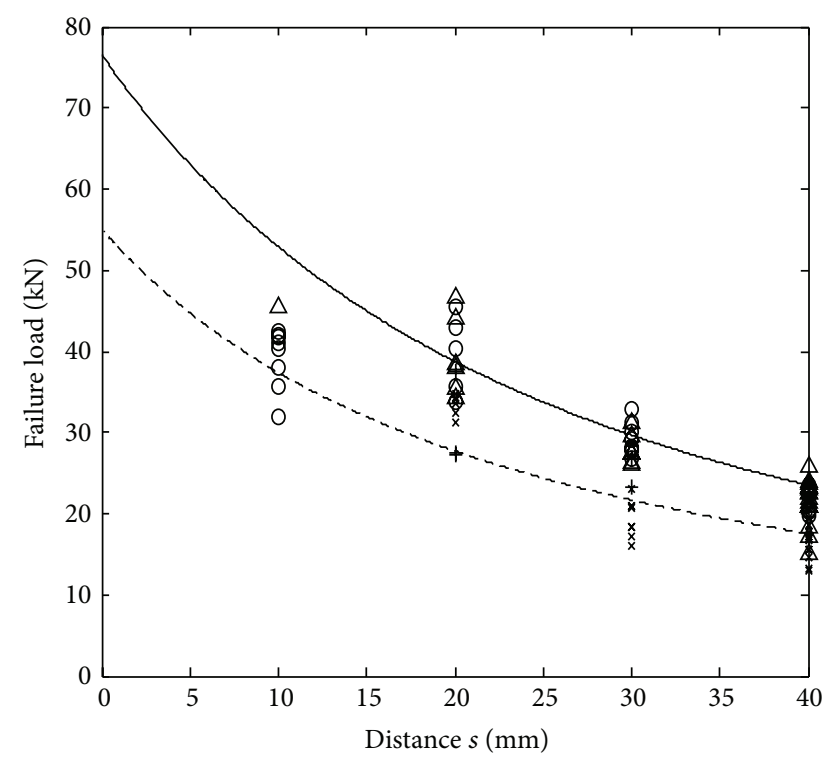

O Study A, PD

+ Study A, PU

- Eq. (13)

$\triangle$ Study B, PD

$\times$ Study B, PU

(a)

(b)

FIGURE 14: Comparison between theory and experiments for vertical cracking of a bottom rail assuming a finite initial crack length. (a) Specimens with single-sided sheathing and (b) specimens with double-sided sheathing. $\mathrm{PD}=$ pith downwards, $\mathrm{PU}=$ pith upwards. 


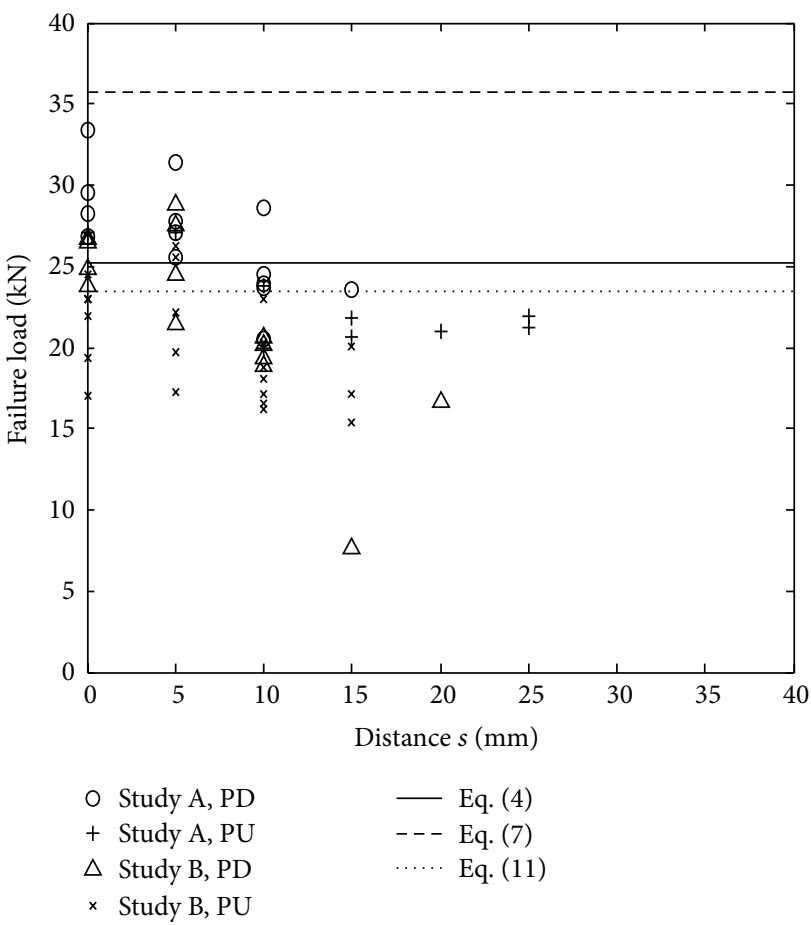

(a)

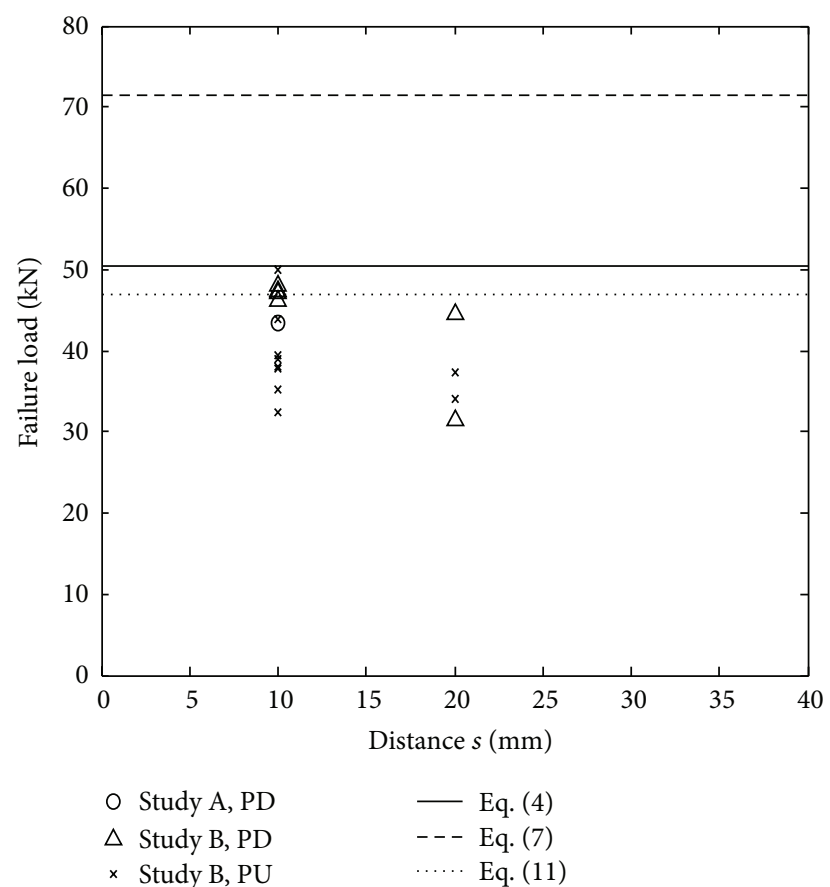

(b)

FIGURE 15: Comparison between theory and experiments for horizontal cracking of a bottom rail. (a) Specimens with single-sided sheathing and (b) specimens with double-sided sheathing. PD = pith downwards, PU = pith upwards.

apply, and further $f_{t}=2.5 \mathrm{MPa}$ has been assumed. Again $l_{e}=s+c, c=20 \mathrm{~mm}$, has been assumed.

While (13) in general seems to slightly overestimate the failure load for $c=20 \mathrm{~mm}$, (22) in general slightly underestimates the failure load. Equation (13) with the use of (35), (23), and (28) leads to approximately equally good agreement with the experimental data.

In Figure 15, (4), (7), and (11), which correspond to Models 1, 2, and 3, respectively, are for horizontal crack propagation (mode 2 ) compared with the experimental data. Figure 15(a) refers to specimens with single-sided sheathing, while Figure 15(b) refers to specimens with double-sided sheathing. All three equations are based on the assumption that failure occurs for $a \rightarrow 0$. The same material properties as used in Figure 14 together with $h=45 \mathrm{~mm}$ and $h_{e}=22.5 \mathrm{~mm}$ are used here.

Equation (11) gives a slightly better prediction of the failure load than does (4). Equation (3) used together with (35) gives very precisely the same failure load as (11). Here it may for practical reasons be recommended to use the simpler (4). It is, however, again emphasized that (11) takes into account the total depth of the bottom rail while (3)-(4) do not. If the theory is applied to bottom rails with larger depths and the sheathing is nailed to the bottom rail close to the bottom of the bottom rail, it may be significant to take into account this effect.

In Caprolu et al. [22], another comparative study concerning the different models presented in this paper was presented but it compares them with other detailed experimental results, including parameter tests. The experimental study was divided into three parts with specimens matched to each other: (1) first the splitting capacity and failure mode of bottom rails subjected to uplift were studied; (2) then material properties such as tensile strength perpendicular to the grain were studied; and (3) fracture energy was determined by testing specimens cut from the specimens belonging to study (1). The experimental results were compared with the present models, using as input values results from (2) and (3). Almost all tested models did show good agreement with the test results.

\section{Conclusions}

New alternative analytical models based on fracture mechanics were presented and compared with an existing model for determination of the failure load of bottom rails subjected to uplift in partially anchored timber frame shear walls. All the models presented are based on the compliance method of fracture mechanics, and the compliance is determined using simple beam theory. Beam theory is formally not applicable to situations where the beam length is short as compared with the beam depth as is often the case in the applications to fracture problems. However, the compliance according to the simple beam theory has previously shown remarkably good results when used in fracture mechanics analysis of, for 
example, end-notched beams and bolted connections loading beams perpendicular to the grain.

In addition to the formal problems associated with the use of beam theory for very short beams, the bottom rail analysis also includes the difficulty that it is a $3 \mathrm{D}$-problem. This is due to the fact that the bottom rail is anchored to the foundation by means of anchor bolts with washers placed along the length of the bottom rail with spacing relatively large as compared with the cross section dimensions of the bottom rail. The analytical models are $2 \mathrm{D}$-models, and the boundary conditions assumed in the 2D-models cannot be valid for all positions along the bottom rail. However, in spite of the seemingly oversimplified analysis, several of the models presented in this paper were found capable of giving failure load predictions in surprisingly good agreement with the experimental data. The only minor empirical adjustment made in the models is assuming that the length of the beam considered in the models for analysis of a vertically propagating crack is the distance from the loaded edge of the bottom rail to the nearest edge of the washer plus an empirically estimated length of $20 \mathrm{~mm}$.

For vertically propagating cracks, the existing model was found to produce excellent predictions if assuming a certain initial crack length as estimated theoretically. A new alternative model was found to produce equally good predictions if assuming that the failure load is obtained for zero crack length.

For horizontally propagating cracks, the experimental data show considerably larger variation and the goodness of the models is harder to estimate. However, a new model based on a semiempirically modified quasinonlinear fracture mechanics approach was found to produce equally good predictions as the existing model. The new model has previously been applied with considerable success to analysis of splitting in beams loaded perpendicular to the grain by bolted connections and has the advantage of taking into account the total depth of the bottom rail. This effect may become significant if bottom rails with larger depths are to be analysed.

In addition to failure load prediction, the capability of the simple analytical models to predict the crack propagation including change of direction of the crack was explored. The predictions seem roughly in agreement with the available experimental data. However, lack of sufficient experimental data and the large variation in the available data does not allow for any firm conclusions to be drawn.

A final comparison between failure modes, with respect to the crack length, shows that the models are able to reflect the tests results with respect to the failure modes.

\section{Code Implications}

When partially anchored shear walls are used, it is necessary to specify the design of the anchoring of the bottom rail. Eurocode 5 does not give any recommendations concerning these things. The testing standard EN 594 recommends that washers of $50 \mathrm{~mm}$ diameter should be used for a $90 \mathrm{~mm}$ wide and $38 \mathrm{~mm}$ thick framing. For other widths and thicknesses of the timber framing, recommendations are needed in Eurocode 5 .
It is important to establish design rules with respect to splitting failure of the bottom rail. There is a clear relationship between the failure loads versus the distance from the edge of the washer to the loaded edge of the bottom rail.

The results of this study and the study by Caprolu et al. [22] show that the failure load of the bottom rail subjected to uplift is, for vertical splitting failure, the minimum value of the failure loads given by (33) due to bending and (13) or (23) due to vertical cracking and, for horizontal splitting failure, by (31) due to bending and (3) or (11) due to horizontal cracking.

\section{Appendix}

\section{Perpendicular-to-Grain Tensile Strength and Effects of Knots}

The perpendicular-to-grain tensile strength of wood is known to be volume dependent. This effect is often explained by means of the Weibull weakest link theory. A large volume subjected to a certain stress shows lower strength than a small volume subjected to the same stress. This volume effect poses a problem for fracture problems since the high perpendicular-to-grain stresses only occur in a very small volume at the crack-tip.

The volume effect is also present for wood subjected to parallel-to-grain stresses. Here we may find mean tensile strengths of $100 \mathrm{MPa}$ for small clear-wood specimens of ordinary softwood species, while the characteristic value for $\mathrm{C} 24$ according to EN 338 is $14 \mathrm{MPa}$.

In Jensen et al. [41], the perpendicular-to-grain tensile strength of Radiata Pine LVL was determined by testing on $45 \times 70 \times 240 \mathrm{~mm}^{3}$ volumes. The mean value was found to be $1.5 \mathrm{MPa}$. The characteristic value was $1.2 \mathrm{MPa}$. It is a well-established fact that Radiata Pine LVL has a lower perpendicular-to-grain tensile strength than Radiata Pine solid wood.

The high perpendicular-to-grain tensile stresses at the crack-tip occur in volumes much smaller than the tested 45 $\times 70 \times 240 \mathrm{~mm}^{3}$ volumes.

In Jensen and Gustafsson [42], the perpendicular-tograin tensile strength of Japanese Cedar was determined using small hour-glass shaped test specimens. The failure load was recorded and the tensile strength was determined as the failure load divided by the smallest cross section area. Most of the specimens did not fail at the smallest cross section, and the tensile strength at the smallest cross section is thus higher than the determined value. The tensile strength was found to be $4.1 \mathrm{MPa}$ with a standard deviation of $1.3 \mathrm{MPa}$.

Japanese Cedar has a relatively low density and is in general considered to be considerably weaker than Nordic softwood.

In problems as considered in the manuscript, the fracture plane is predetermined by the location of the nails. In the same way, the smallest cross section in the tested hourglass shaped specimens is predetermined. It is unlikely that the weakest link is located in the fracture plane just at the crack-tip, and therefore the tensile strength relevant for the considered fracture problems should be expected to be 
considerably higher than those determined for construction size timber.

The fracture models presented do not explicitly consider the effect of knots. It may be said that the models in the usual way include knots through the material properties.

However, for mode I fracture problems of wood, knots do in fact not decrease the strength. Very much on the contrary, knots at the vicinity of crack-tips often severely increase the strength. This is again due to the fact that the perpendicularto-grain tensile stresses at the crack-tips occur in very small volumes. The grain of the wood wraps around the knot hole, and the grain direction just in front of a knot is often virtually perpendicular to the crack plane, that is, we get tensile stresses parallel to the grain here.

The first author has personally tested numerous beams and so-called plate specimens (see Jensen et al. [41]; Jensen and Gustafsson [42]) with bolts loading timber perpendicular to the grain and causing splitting. Knots always serve as reinforcement in such splitting problems. In several cases, test specimens with knots in the vicinity of the crack-tip had to be omitted since they resulted in absurdly high failure loads and caused very large embedment before failing.

\section{Competing Interests}

The authors declare that they have no competing interests.

\section{Acknowledgments}

The authors would like to give their sincere thanks for the financial support from the County Administrative Board in Norrbotten, the Regional Council of Västerbotten, and the European Union: European Regional Development Fund, Regional Structural Fund, and Interregional Programmes.

\section{References}

[1] B. Källsner and U. A. Girhammar, "Plastic design of partially anchored wood-framed wall diaphragms with and without openings," in Proceedings of the Annual CIB-W18 Timber Structures Meeting, paper 38-15-7, Karlsruhe, Germany, 2005.

[2] Eurocode 5, "Design of timber structures-part 1-1: generalcommon rules and rules for buildings," EN 1995-1-1, European Committee for Standardization, Brussels, Belgium, 2003.

[3] European Committee for Standardization, "Timber structures-test methods-racking strength and stiffness of timber frame wall panels," European Standard CEN/TC 124, EN 594:2008, European Committee for Standardisation (CEN), Brussels, Belgium, 2008.

[4] H. G. L. Prion and F. Lam, "Shear walls and diaphragms," in Timber Engineering, S. Thelandersson and H. J. Larsen, Eds., chapter 20, pp. 383-408, John Wiley \& Sons, Chichester, UK, 2003.

[5] C. Ni and E. Karacabeyli, "Capacity of shear wall segments without hold-downs," Wood Design Focus, vol. 12, no. 2, pp. 10$17,2002$.

[6] T. Hirai, K. Namura, K. Yanaga, Y. Sasaki, and A. Koizumi, "Design lateral resistance of rows of anchor-bolt joints," in Proceedings of the 8th World Conference on Timber Engineering, vol. III, pp. 251-254, Lahti, Finland, 2004.
[7] T. Hirai, K. Namura, K. Yanaga, A. Koizumi, and T. Tsujino, "Lateral resistance of anchor-bolt joints between timber sills and foundations-II. Effective lateral resistance of multiple anchor-bolt joints," Journal of Wood Science, vol. 52, no. 2, pp. 115-120, 2006.

[8] T. Hirai, K. Namura, T. Kimura, T. Tsujino, and A. Koizumi, "Lateral resistance of anchor-bolt joints between timber sills and foundations III: numerical simulations of the effect of sill thickness on the effective lateral resistance of multiple anchorbolt joints," Journal of Wood Science, vol. 52, no. 4, pp. 295-301, 2006.

[9] K. Namura, K. Yanaga, Y. Sasaki, A. Koizumi, and T. Hirai, "Lateral resistance of anchor-bolt joints between timber-sills and foundations-I. Single-shear tests of anchor-bolt joints of Japanese post and beam constructions," Mokuzai Gakkaishi, vol. 51, no. 2, pp. 110-117, 2005 (Japanese).

[10] K. Leitch, R. Hairstans, D. Abbott, R. Dodyk, and S. McAndrew, "Experimental study of timber-to-concrete dowel type connections used in timber platform frame," in Proceedings of the 10th World Conference on Timber Engineering, pp. 1461-1468, Miyazaki, Japan, June 2008.

[11] K. Leitch, The development of a hybrid racking panel [Ph.D. thesis], School of Engineering and Built Environment, Edinburgh Napier University, Edinburgh, UK, 2013.

[12] J. M. Menendez, K. Leitch, and R. Hairstans, "Sole plate fixing details for modern methods of timber construction," in Materials and Joints in Timber Structures: Recent Developments of Technology, S. Aicher, H.-W. Reinhardt, and H. Garrecht, Eds., vol. 9 of RILEM Book Series, pp. 109-118, Springer, Berlin, Germany, 2014.

[13] K. A. Duchateau, Structural design and performance of composite wall-foundation connector elements [M.S. thesis], Washington State University, Department of Civil and Environment Engineering, Pullman, Wash, USA, 2005.

[14] B. Yeh and T. G. Williamson, "Combined shear and wind uplift resistance of wood structural panel shearwalls," in Proceedings of the CIB-W18 Meeting, Paper 41-15-6, St. Andrews, Canada, 2008.

[15] NAHB, "Full-scale tensile and shear wall performance testing of light-frame wall assemblies sheathed with windstorm OSB panels," Test Report 4105-008, NAHB Research Center, Upper Marlboro, Md, USA, 2005.

[16] U. A. Girhammar and B. Källsner, "Design against brittle failure of bottom rails in shear walls," Proceedings of the Institution of Civil Engineers-Structures and Buildings, vol. 169, no. 10, pp. 782-793, 2016.

[17] E. Serrano, J. Vessby, and A. Olsson, "Modeling of fracture in the sill plate in partially anchored shear walls," Journal of Structural Engineering, vol. 138, no. 10, pp. 1285-1288, 2012.

[18] G. Caprolu, U. A. Girhammar, and B. Källsner, "Analytical models for splitting capacity of bottom rails in partially anchored timber frame shear walls based on fracture mechanics," Wood Material Science \& Engineering, 2015.

[19] E. Serrano, J. Vessby, A. Olsson, U. A. Girhammar, and B. Källsner, "Design of bottom rails in partially anchored shear walls using fracture mechanics," in Proceedings of the CIB-W18 Timber Structures Meeting, paper 44-15-4, Alghero, Italy, 2011.

[20] G. Caprolu, U. A. Girhammar, B. Källsner, and H. Lidelöw, "Splitting capacity of bottom rail in partially anchored timber frame shear walls with single-sided sheathing," IES Journal Part A: Civil and Structural Engineering, vol. 7, no. 2, pp. 83-105, 2014.

[21] G. Caprolu, U. A. Girhammar, and B. Källsner, "Splitting capacity of bottom rails in partially anchored timber frame shear 
walls with double-sided sheathing," IES Journal Part A: Civil and Structural Engineering, vol. 8, no. 1, pp. 1-23, 2015.

[22] G. Caprolu, U. A. Girhammar, and B. Källsner, "Comparison of models and tests on bottom rails in timber frame shear walls experiencing uplift," Construction and Building Materials, vol. 94, article 6732, pp. 148-163, 2015.

[23] EN, "Structural timber-strength classes," EN 338, European Committee for Standardization, Brussels, Belgium, 2009.

[24] EN 622-2, Fibreboards-Specifications-Part 2: Requirements for Hardboard, European Committee for Standardization, Brussels, Belgium, 2004.

[25] K. Hellan, Introduction to Fracture Mechanics, McGraw-Hill, New York, NY, USA, 1984.

[26] P. Haller and P. J. Gustafsson, "An overview of fracture mechanics concepts. Fracture mechanics models for strength analysis of timber beams with a hole or a notch," A Report of RILEM TC-133, P. J. Gustafsson, ed. TVSM-7134, Division of Structural Mechanics, Lund University, Lund, Sweden, 2002.

[27] H. Petersson, "Energy Release Rate Analysis", Fracture Mechanics Models for Strength Analysis of Timber Beams with a Hole or a Notch-A Report of RILEM TC-133, TVSM-7134, Lund University, Lund, Sweden, 2002, Edited by P. J. Gustafsson.

[28] P. J. Gustafsson, "Fracture perpendicular to grain-structural applications," in Timber Engineering, S. Thelandersson and H. J. Larsen, Eds., John Wiley \& Sons, Chichester, UK, 2003.

[29] I. Smith, E. Landis, and M. Gong, "Principle of fracture mechanics," in Fracture and Fatigue in Wood, I. Smith, E. Landis, and M. Gong, Eds., pp. 67-97, John Wiley \& Sons, Chichester, UK, 2003.

[30] E. Serrano and P. J. Gustafsson, "Fracture mechanics in timber engineering-strength analyses of components and joints," Materials and Structures, vol. 40, no. 1, pp. 87-96, 2007.

[31] C. Ni and E. Karacabeyli, "Design of shear walls without holddowns," in Proceedings of theCIB-W18 Timber Structures Meeting, Paper 38-15-4, Karlsruhe, Germany, 2005.

[32] J. Vessby, E. Serrano, A. Olsson, U. A. Girhammar, and B. Källsner, "Simulation of bottom rail fracture in partially anchored shear walls using XFEM," in Proceedings of the CIBW18 Timber Structures Meeting, Växjö, Sweden, 2012.

[33] P. J. Gustafsson, "A study of strength of notched beams," in Proceedings of the CIB-W18 Timber Structures Meeting, Paper 2110-1, Vancouver, Canada, 1988.

[34] J. L. Jensen, "Quasi-non-linear fracture mechanics analysis of splitting failure in moment-resisting dowel joints," Journal of Wood Science, vol. 51, no. 6, pp. 583-588, 2005.

[35] T. A. C. M. van der Put and A. J. M. Leijten, "Evaluation of perpendicular to grain failure of beams caused by concentrated loads of joints," in Proceedings of the CIB-W18 Timber Structures Meeting, paper 33-7-7, Delft, The Netherlands, 2000.

[36] L. Boström, Method for determination of the softening behaviour of wood and the applicability of a nonlinear fracture mechanics model [Ph.D. thesis], Report TVBM-1012, Division of Building Materials, Lund University, Lund, Sweden, 1992.

[37] S. Holmberg, "A numerical and experimental study of initial defibration of wood," Doctoral Thesis Report TVSM-1010, Division of Structural Mechanics, Lund University, Lund, Sweden, 1998.

[38] F. E. Siimes, "The effect of specific gravity, moisture content, temperature and heating time on the tension and compression strength and elasticity properties perpendicular to the grain of finnish pine spruce and birch wood and the significance of these factors on the checking of timber at kiln drying," Julkaisu
84, VTT-The Technical Research Centre of Finland, Espoo, Finland, 1967.

[39] A. Reiterer, S. E. Stanzl-Tschegg, and E. K. Tschegg, "Mode I fracture and acoustic emission of softwood and hardwood," Wood Science and Technology, vol. 34, no. 5, pp. 417-430, 2000.

[40] H. J. Larsen and P. H. J. Gustafsson, "The fracture energy of wood in tension perpendicular to the grain-results from a joint testing project," in Proceedings of the CIB-W18A Timber Structures Meeting, Paper 23-19-2, Lisbon, Portugal, 1990.

[41] J. L. Jensen, P. Quenneville, U. A. Girhammar, and B. Källsner, "Splitting of timber beams loaded perpendicular to grain by connections-combined effect of edge and end distance," Construction and Building Materials, vol. 35, pp. 289-293, 2012.

[42] J. L. Jensen and P.-J. Gustafsson, "Shear strength of beam splice joints with glued-in rods," Journal of Wood Science, vol. 50, no. 2, pp. 123-129, 2004. 


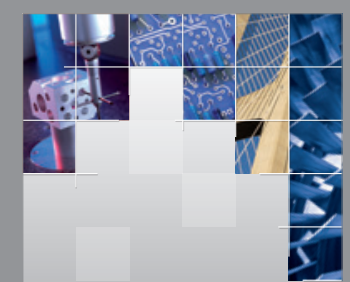

\section{Enfincering}
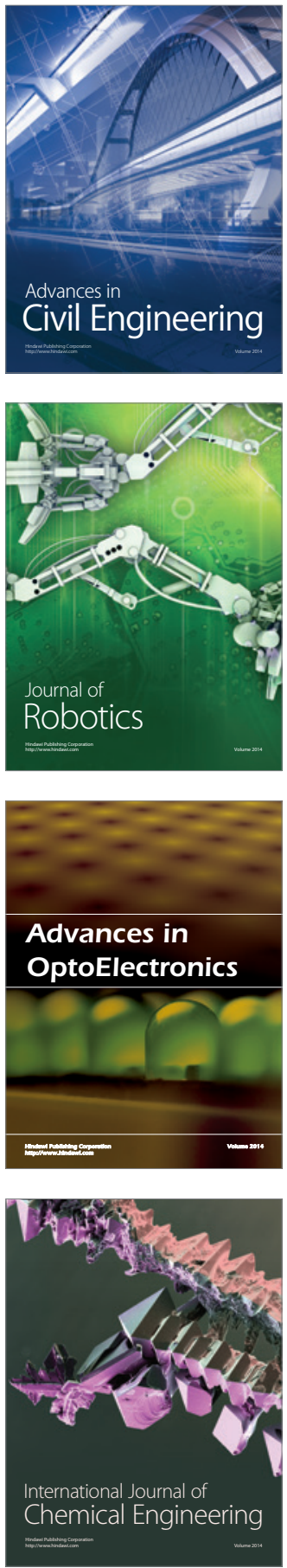

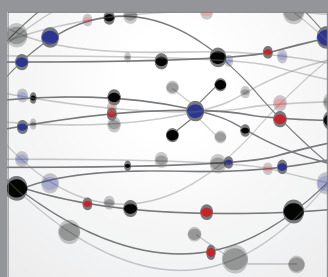

The Scientific World Journal

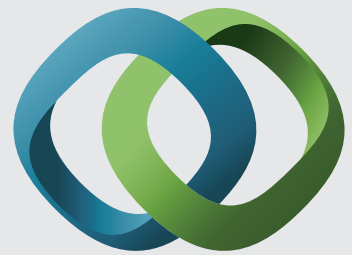

\section{Hindawi}

Submit your manuscripts at

http://www.hindawi.com
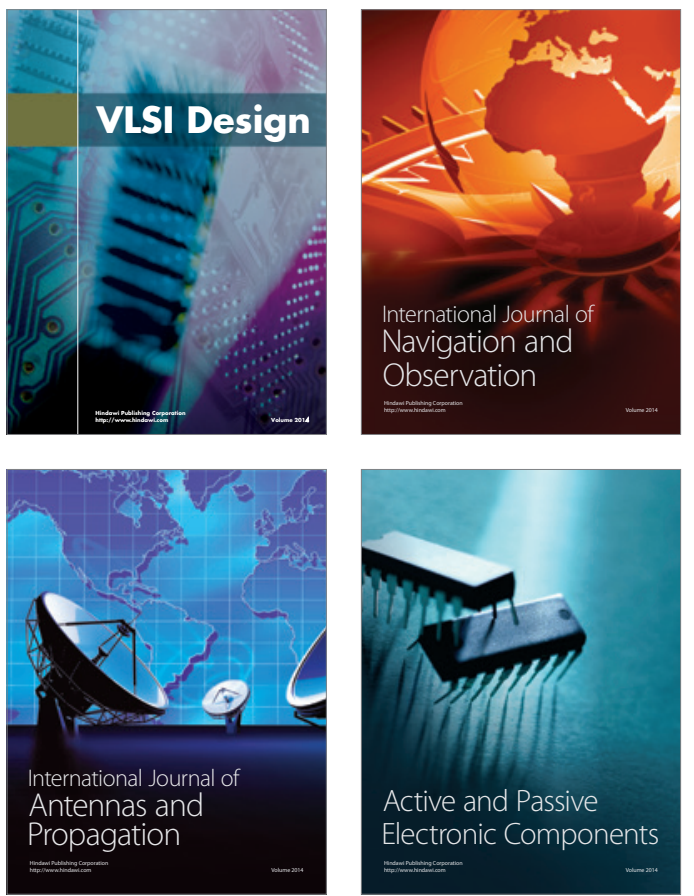
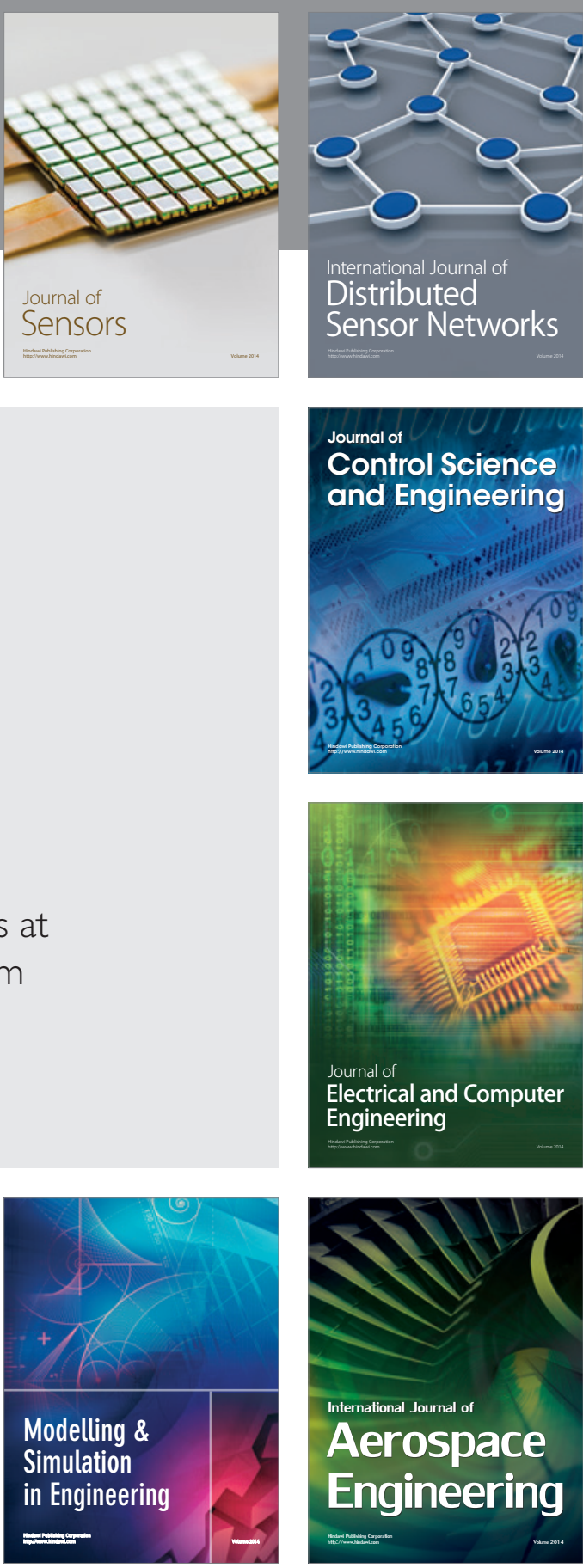

International Journal of

Distributed

Sensor Networks

Journal of

Control Science

and Engineering
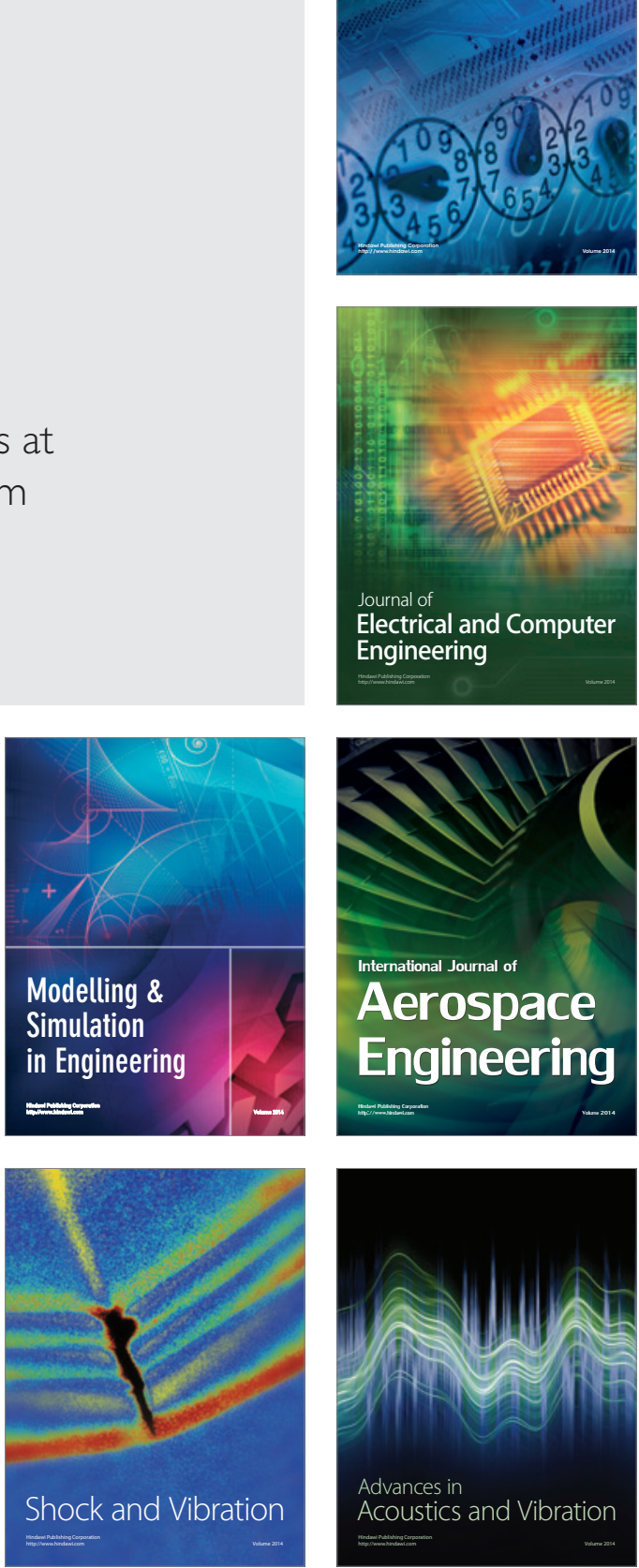